\title{
Optical and microphysical properties of smoke over Cape Verde inferred from multiwavelength lidar measurements
}

\author{
By MATTHIAS TESCHE ${ }^{1,2, *}$, DETLEF MÜLLER ${ }^{1,3}$, SILKE GROSS ${ }^{4,5}$, ALBERT ANSMANN ${ }^{1}$, \\ DIETRICH ALTHAUSEN ${ }^{1}$, VOLKER FREUDENTHALER ${ }^{4}$, BERNADETT WEINZIERL ${ }^{6}$, \\ ANDREAS VEIR A ${ }^{6}$ and A NDREAS PETZOLD ${ }^{6}, \quad{ }^{1}$ Leibniz Institute for Tropospheric Research (IfT), \\ Permoserstraße 15, 04318 Leipzig, Germany; ${ }^{2}$ now at Department of Environmental Science (ITM), Stockholm \\ University, Svante Arrhenius väg 8c, 10691 Stockholm, Sweden; ${ }^{3}$ Atmospheric Remote Sensing Laboratory, Gwangju \\ Institute of Science and Technology, Gwangju 500-712, Republic of Korea; ${ }^{4}$ Meteorological Institute, \\ Ludwig-Maximilians-Universität, Theresienstraße 37, 80333 Munich, Germany; ${ }^{5}$ Institute of Atmospheric Physics, \\ German Aerospace Center (DLR), Oberpfaffenhofen, 82234 Wessling, Germany; ${ }^{6}$ now at Institute for Atmospheric \\ Physics, German Aerospace Center (DLR), Oberpfaffenhofen, 82234 Wessling, Germany
}

(Manuscript received 31 October 2010; in final form 13 May 2011)

\begin{abstract}
Lidar measurements of mixed dust/smoke plumes over the tropical Atlantic ocean were carried out during the winter campaign of SAMUM-2 at Cape Verde. Profiles of backscatter and extinction coefficients, lidar ratios, and Ångström exponents related to pure biomass-burning aerosol from southern West Africa were extracted from these observations. Furthermore, these findings were used as input for an inversion algorithm to retrieve microphysical properties of pure smoke. Seven measurement days were found suitable for the procedure of aerosol-type separation and successive inversion of optical data that describe biomass-burning smoke. We inferred high smoke lidar ratios of $87 \pm 17 \mathrm{sr}$ at $355 \mathrm{~nm}$ and $79 \pm 17 \mathrm{sr}$ at $532 \mathrm{~nm}$. Smoke lidar ratios and Ångström exponents are higher compared to the ones for the dust/smoke mixture. These numbers indicate higher absorption and smaller sizes for pure smoke particles compared to the dust/smoke mixture. Inversion of the smoke data set results in mean effective radii of $0.22 \pm 0.08 \mu \mathrm{m}$ with individual results varying between 0.10 and $0.36 \mu \mathrm{m}$. The single-scattering albedo for pure biomass-burning smoke was found to vary between 0.63 and 0.89 with a very low mean value of $0.75 \pm 0.07$. This is in good agreement with findings of airborne in situ measurements which showed values of $0.77 \pm 0.03$. Effective radii from the inversion were similar to the ones found for the fine mode of the in situ size distributions.
\end{abstract}

\section{Introduction}

In the companion paper (Tesche et al., 2011) we report on optical properties of aerosol particles observed during SAMUM-2 at Cape Verde (disregarding the state of mixture of dust and smoke). Here, we present the results obtained by analysing the spectrally resolved lidar observations together with polarization lidar measurements (Groß et al., 2011a). This combination can be used to retrieve the contribution of individual aerosol types to the observed mixed particle layers (Tesche et al., 2009b; Groß et al., 2011a). The aerosol-type separation approach that is described in detail in Tesche et al. (2009b) allows us to separate the

\footnotetext{
* Corresponding author.

e-mail: matthias.tesche@itm.su.se

DOI: $10.1111 /$ j.1600-0889.2011.00549.x
}

dust and smoke contributions to the measured optical properties and to derive the optical and microphysical properties of pure biomass-burning smoke particles.

The results presented below may contribute to an improved description of smoke aerosols in atmospheric models. Biomassburning aerosol in subtropical and tropical regions were investigated during SAFARI-2000 (Bergstorm et al., 2003; Eck et al., 2003; Haywood et al., 2003), SCAR-B (Reid et al., 1998a,b), INDOEX (Ansmann et al., 2000; Franke et al., 2001, 2003; Müller et al., 2003), and AMMA (Capes et al., 2008; Haywood et al., 2008; Heese and Wiegner, 2008; Johnson et al., 2008a,b; Pelon et al., 2008). The general finding is that smoke particles mostly consist of soot and have a rather low single-scattering albedo (SSA) that is clearly below 0.9 at visible wavelengths. Due to their high absorption, smoke particles cause radiative heating (Keil et al., 2003; Myhre et al., 2008; 
Bauer et al., 2011; Heinold et al., 2011). Investigations of pure biomass-burning aerosol under ambient conditions are scarce, because measurements are usually performed with the dried aerosol sample (Reid et al., 2005). Lidar observations of pure smoke plumes are also rare, because most established lidar sites are located far away from the regions of biomass-burning activity and rely on favourable meteorological conditions to detect (mostly diluted) plumes after thousands of kilometres of longrange transport (Müller et al., 2005).

From 15 January to 14 February 2008 the second field campaign of the Saharan Mineral Dust Experiment (SAMUM-2, Ansmann et al., 2011) was conducted at the airport of Praia, Cape Verde $\left(15.0^{\circ} \mathrm{N}, 23.5^{\circ} \mathrm{W}, 75 \mathrm{~m}\right.$ height above sea level, asl). Advanced multiwavelength Raman/polarization lidar measurements of stratified plumes of dust from northern Africa and elevated mixed dust/smoke plumes from southern West Africa were performed (Groß et al., 2011a,b; Tesche et al., 2009b, 2011). This paper presents an in-depth investigation of the lidar measurements presented by Tesche et al. (2011). To fully exploit the SAMUM-2 measurements and to derive microphysical particle properties of the biomass-burning smoke in the mixed dust/smoke plume, we try to identify the individual contributions of the two aerosol types to the measured total optical properties (Tesche et al., 2009b). By subtracting the influence of the non-spherical mineral dust particles to the measured backscatter and extinction profiles, we obtain a data set for the contribution of pure biomass-burning smoke. This data set can then be used as input to a microphysical inversion algorithm (Müller et al., 1999, 2000a; Veselovskii et al., 2002). This algorithm cannot be applied to data containing any influence of large non-spherical mineral dust particles because their interaction with light cannot be described properly with Mie scattering theory, which is used as theoretical basis of the inversion methodology.

After a brief description of the SAMUM-2 instrumental setup with respect to lidar and airborne in situ measurements in Section 2 we review the aerosol-type-separation method and the inversion algorithm in Section 3. Detailed results for two example days and the remaining observations are presented in Section 4. In Sections 4.1 and 4.3, inversion results are also compared to airborne in situ measurements of the particle size distribution and the SSA. General findings and a discussion are presented in Section 5. A comparison to results of further in situ measurements performed in the framework of SAMUM-2 is given in Section 6 before the paper closes with a summary in Section 7.

\section{Instrumentation}

\subsection{Lidar}

For this study, we used profiles of backscatter and extinction coefficients measured with the Backscatter Extinction lidar-
Ratio Temperature Humidity Apparatus (BERTHA, Tesche et al., 2009a) of the Leibniz Institute for Tropospheric Research (IfT), Leipzig, and particle depolarization ratio profiles inferred with the MUltiwavelenth LIdar System (MULIS, Freudenthaler et al., 2009) of the Meteorological Institute of the University of Munich. MULIS' high-quality profiles of the volume and particle depolarization ratio at $532 \mathrm{~nm}$ are vital for the application of the aerosol-type separation (Tesche et al., 2009b). The analysis of the lidar measurements was performed as is described in Freudenthaler et al. (2009), Groß et al. (2011a), and Tesche et al. (2009a, 2011).

\subsection{Airborne in situ measurements}

During SAMUM-2, airborne in situ measurements of the particle size distribution, the depth of aerosol layers and their mixing state, and the absorption coefficient were conducted aboard the Falcon research aircraft of the German Aerospace Center (DLR). In this work, we compare effective radii and values of the singlescattering albedo derived from in situ measurements that are assumed to represent smoke conditions to the findings of the inversion of pure biomass-burning smoke data sets (Section 3). Details about the measurement of the particle size distribution up to $30 \mu \mathrm{m}$ and of the absorption coefficient can be found in Weinzierl et al. (2011). The latter quantity was obtained with a 3- $\lambda$ Particle Soot Absorption Photometer (PSAP) as described in Virkkula et al. (2005), whereupon the correction of the PSAP raw signal was performed with the latest correction factors presented by Virkkula (2010). The complex refractive index is derived from size distribution and absorption measurements by means of the so-called PSAP data inversion scheme (Petzold et al., 2009). It is assumed that the measured particles are spherical. The inversion uses the fact that only few combinations of the (measured) aerosol size distribution and the (assumed) real and imaginary part of the refractive index provide the right input data for a Mie scattering code (Bohren and Huffman, 1983) to reconstruct the measured absorption coefficients at the three PSAP wavelengths of 467, 530, and $660 \mathrm{~nm}$. The refractive index combination that reduces the difference between measured and reconstructed absorption coefficients to values below 1-3\% at all three wavelengths constitutes the solution of the retrieval. Besides the absorption coefficient and the complex refractive index, this inversion also provides results for the scattering coefficient. With this information the single-scattering albedo can be calculated. The error bars of the SSA presented in this paper are obtained through a sensitivity study by varying the input parameters of the PSAP inversion within the maximum range of the measurement uncertainty.

\section{Theory}

This section reviews the method of aerosol-type separation (Tesche et al., 2009b) and the subsequently applied inversion 
with regularization (Müller et al., 1999, 2000a; Veselovskii et al., 2002; Ansmann and Müller, 2005). Detailed descriptions can be found in the respective papers.

\subsection{Aerosol-type separation}

Tesche et al. (2009b) present a method for the separation of the contributions of individual types of aerosols to the optical properties of an aerosol mixture measured with a combination of multiwavelength and polarization lidar systems. For the separation, it is assumed that two types of differently depolarizing aerosol particles are present in an external mixture. The method uses the intrinsic characteristics of the linear particle depolarization ratio measured with lidar (Sassen, 2005): it mainly depends on the shape of the scattering particles and is zero for perfect spheres (e.g. water droplets or small anthropogenic aerosols) whereas it increases with increasing particle non-sphericity. The highest values of up to 0.5 are observed for ice crystals. Together with other lidar-specific intensive properties like the extinctionto-backscatter (lidar) ratio and the Angström exponent (which describes the spectral slope of the backscatter or extinction coefficient, Ångström, 1964), the particle depolarization ratio can be used for lidar-based aerosol characterization (e.g. Müller et al., 2007; Groß et al., 2011a; Tesche et al., 2011). The aerosoltype separation approach as presented here and in Tesche et al. (2009b) relies on the findings of SAMUM-1 for pure dust in Morocco and on high-quality measurements of the linear particle depolarization ratio during SAMUM-2.

To separate the contributions of depolarizing (index d, e.g. mineral dust) and non-depolarizing (index nd, e.g. biomassburning smoke) particles, we start with the equation for the particle depolarization ratio

$\delta_{\lambda}^{\mathrm{p}}=\frac{\beta_{\lambda}^{\mathrm{m}}\left(\delta_{\lambda}^{\mathrm{v}}-\delta_{\lambda}^{\mathrm{m}}\right)+\beta_{\lambda}^{\mathrm{p}} \delta_{\lambda}^{\mathrm{v}}\left(1+\delta_{\lambda}^{\mathrm{m}}\right)}{\beta_{\lambda}^{\mathrm{m}}\left(\delta_{\lambda}^{\mathrm{m}}-\delta_{\lambda}^{\mathrm{v}}\right)+\beta_{\lambda}^{\mathrm{p}}\left(1+\delta_{\lambda}^{\mathrm{m}}\right)}$.

This intensive parameter is calculated from the volume depolarization ratio $\delta_{\lambda}^{\mathrm{v}}$, the particle backscatter coefficient $\beta_{\lambda}^{\mathrm{p}}$, the molecular depolarization ratio $\delta_{\lambda}^{\mathrm{m}}$ and the molecular backscatter coefficient $\beta_{\lambda}^{\mathrm{m}}$.

As in the derivation of eq. (1), for which $\delta_{\lambda}^{\mathrm{v}}$ is assumed to comprise contributions of particles and molecules, it is now assumed that $\delta_{\lambda}^{\mathrm{p}}$ contains contributions of depolarizing and nondepolarizing particles (Tesche et al., 2009b)

$\delta_{\lambda}^{\mathrm{p}}=\frac{{ }^{\perp} \beta_{\lambda}^{\mathrm{d}}+{ }^{\perp} \beta_{\lambda}^{\text {nd }}}{{ }^{\|} \beta_{\lambda}^{\mathrm{d}}+{ }^{\|} \beta_{\lambda}^{\text {nd }}}$.

The relationships

$\beta_{\lambda}^{\mathrm{x}}={ }^{\perp} \beta_{\lambda}^{\mathrm{x}}+{ }^{\|} \beta_{\lambda}^{\mathrm{x}}$,

${ }^{\|} \beta_{\lambda}^{\mathrm{x}}=\frac{\beta_{\lambda}^{\mathrm{x}}}{1+\delta_{\lambda}^{\mathrm{x}}}$ and

${ }^{\perp} \beta_{\lambda}^{\mathrm{x}}=\frac{\beta_{\lambda}^{\mathrm{x}} \delta_{\lambda}^{\mathrm{x}}}{1+\delta_{\lambda}^{\mathrm{x}}}$

with the index $\mathrm{x}=\mathrm{d}$ or nd are used to replace $\left\|\beta_{\lambda}^{\mathrm{d}},\right\| \beta_{\lambda}^{\text {nd }}, \perp \beta_{\lambda}^{\mathrm{d}}$, and ${ }^{\perp} \beta_{\lambda}^{\text {nd }}$ in eq. (2) to obtain the contributions of depolarizing and non-depolarizing particles to the particle depolarization ratio as

$\delta_{\lambda}^{\mathrm{p}}=\frac{\beta_{\lambda}^{\mathrm{nd}} \delta_{\lambda}^{\mathrm{nd}}\left(1+\delta_{\lambda}^{\mathrm{d}}\right)+\beta_{\lambda}^{\mathrm{d}} \delta_{\lambda}^{\mathrm{d}}\left(1+\delta_{\lambda}^{\mathrm{nd}}\right)}{\beta_{\lambda}^{\mathrm{nd}}\left(1+\delta_{\lambda}^{\mathrm{d}}\right)+\beta_{\lambda}^{\mathrm{d}}\left(1+\delta_{\lambda}^{\mathrm{nd}}\right)}$.

After substituting $\beta_{\lambda}^{\text {nd }}$ by $\beta_{\lambda}^{\mathrm{p}}-\beta_{\lambda}^{\mathrm{d}}$, a solution is obtained for the dust-related backscatter coefficient as

$\beta_{\lambda}^{\mathrm{d}}=\beta_{\lambda}^{\mathrm{p}} \frac{\left(\delta_{\lambda}^{\mathrm{p}}-\delta_{\lambda}^{\mathrm{nd}}\right)\left(1+\delta_{\lambda}^{\mathrm{d}}\right)}{\left(\delta_{\lambda}^{\mathrm{d}}-\delta_{\lambda}^{\mathrm{nd}}\right)\left(1+\delta_{\lambda}^{\mathrm{p}}\right)}$.

Figure 1 is a visualization of eq. (7) for two-component mixtures of maritime aerosol + biomass-burning smoke (green), maritime aerosol + mineral dust (blue), and biomass-burning smoke + mineral dust (red) at $532 \mathrm{~nm}$. The third mixture represents the conditions observed in the elevated layers over Cape Verde during winter described in this paper and in Tesche et al. (2009b, 2011). An investigation of the second aerosol mixture is presented by Groß et al. (2011b). For the separation performed at $532 \mathrm{~nm}$, the particle depolarization ratios for maritime aerosol, biomass-burning smoke, and mineral dust are assumed to be $\delta^{\mathrm{o}}=0.03, \delta^{\mathrm{s}}=0.05 \pm 0.02$, and $\delta^{\mathrm{d}}=0.31 \pm 0.03$, respectively. Detailed measurements of $\delta^{\mathrm{d}}$ were conducted during SAMUM-1 (Freudenthaler et al., 2009). The 532-nm smoke

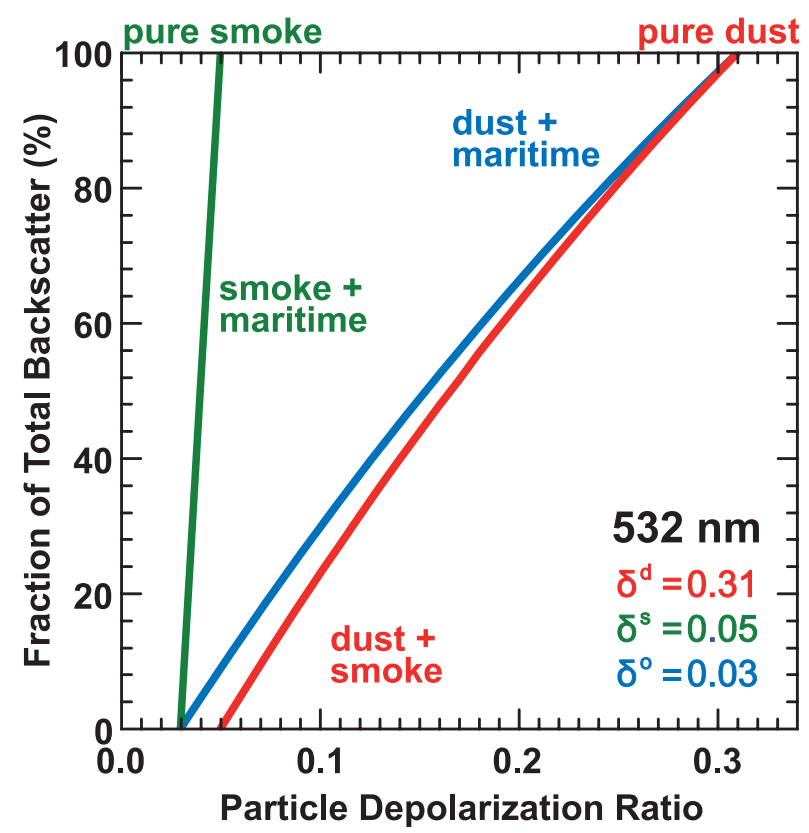

Fig. 1. Visualization of eq. (7) for two-component mixtures of mineral dust, biomass-burning smoke, and maritime aerosol at $532 \mathrm{~nm} . \delta^{\mathrm{d}}, \delta^{\mathrm{s}}$, and $\delta^{\circ}$ are the particle depolarization ratios assumed for the respective aerosol types. 
depolarization ratio was taken from the literature. A discussion of its choice is given in Tesche et al. (2009b). The particle depolarization ratio of maritime aerosol was measured during SAMUM-2 (Groß et al., 2011a,b). It can be seen from the red line in Fig. 1, that for 532-nm particle depolarization ratios of $0.14-0.18$ that were usually observed in the elevated, mixed dust/smoke layers over Cape Verde during winter (Tesche et al., 2011; Groß et al., 2011a), the contribution of dust varies between 40 and $60 \%$. The aerosol-type separation is complicated, if the contrast between the particle depolarization ratios of the individual aerosol types decreases (see green line in Fig. 1).

The profile of the non-dust backscatter coefficient is obtained as $\beta_{\lambda}^{\mathrm{p}}-\beta_{\lambda}^{\mathrm{d}}$. To derive the dust extinction coefficient, the dust backscatter coefficient calculated according to eq. (7) is multiplied by the dust lidar ratio $S_{532}^{\mathrm{d}}$ (Tesche et al., 2009a)

$\sigma_{532}^{\mathrm{d}}=S_{532}^{\mathrm{d}} \beta_{532}^{\mathrm{d}}$.

With the help of the backscatter- and extinction-related Ångström exponents of $\mathrm{a}_{\beta}^{\mathrm{d}}\left(\lambda_{1}, \lambda_{2}\right)=0.2-0.3$ and $\mathrm{a}_{\sigma}^{\mathrm{d}}\left(\lambda_{1}, \lambda_{2}\right)=$ 0 , respectively, for pure dust as measured during SAMUM-1 (Tesche et al., 2009a), one obtains backscatter and extinction coefficients at the other laser wavelength as

$\beta_{\lambda}^{\mathrm{d}}=\beta_{532}^{\mathrm{d}}\left(\frac{532}{\lambda}\right)^{\stackrel{\mathrm{a}}{\beta}_{\beta}^{\mathrm{d}(\lambda, 532)}}$

with $\lambda$ being 355 or $1064 \mathrm{~nm}$,

$\sigma_{355}^{\mathrm{d}}=\sigma_{532}^{\mathrm{d}}\left(\frac{532}{355}\right)^{\mathrm{a}_{\sigma}^{\mathrm{d}}(355,532)}$,

$\beta_{\lambda}^{\mathrm{nd}}=\beta_{\lambda}^{\mathrm{p}}-\beta_{\lambda}^{\mathrm{d}}$

and

$\sigma_{\lambda}^{\mathrm{nd}}=\sigma_{\lambda}^{\mathrm{p}}-\sigma_{\lambda}^{\mathrm{d}}$

Furthermore, estimates of the non-dust lidar ratio $S_{\lambda}^{\text {nd }}=\sigma_{\lambda}^{\text {nd }} / \beta_{\lambda}^{\text {nd }}$ and the non-dust Ångström exponents $\mathrm{a}_{\beta}^{\text {nd }}(355,532), \mathrm{a}_{\beta}^{\text {nd }}(532$, 1064), and $\mathrm{a}_{\sigma}^{\text {nd }}(355,532)$ are obtained.

Finally, the aerosol-type-separation results in a data set of three backscatter coefficients and two extinction coefficients (often referred to as $3+2$ data set) of the non-dust aerosol. This data set can be used as input for an inversion algorithm to retrieve microphysical particle properties from which the SSA can be computed (Section 3.2). In the cases presented in this paper, the subtraction of the contribution of non-spherical mineral dust particles from the measured optical data results in $3+2$ data sets of pure biomass-burning smoke. To further reduce signal noise and the amount of data, mean values for height intervals of $250 \mathrm{~m}$ were calculated for each parameter. In the end, 5-10 3+2 data sets (representing different height levels) for the inversion of one measurement were obtained.

\subsection{Inversion with regularization}

The method of inversion with regularization for multiwavelength lidar measurements was proposed by Müller et al. (1999, 2000a) and improved to less input parameters by Veselovskii et al. (2002). A complete overview of the inversion of multiwavelength lidar measurements is given by Ansmann and Müller (2005) and the references therein. The inversion method proved reliable during various field experiments that included comparisons to in situ particle sampling (Ansmann et al., 2002; Wandinger et al., 2002; Müller et al., 2003, 2005; Tesche et al., 2008). For the state-of-the-art inversion retrieval, a data set of three backscatter coefficients and two extinction coefficients (i.e. a $3+2$ data set) is needed as minimum optical input information (Müller et al., 2001).

For one input data set only a fraction of the solutions of the inversion algorithm represents trustworthy results. This necessitates a careful analysis of the inversion output. In the end, several hundred trustworthy solutions (which show realistic shapes of the particle size distribution) out of hundreds of thousand of mathematical inversion results are averaged. From this analysis of the inversion results of one input data set, we obtain a mean particle number concentration and a mean complex refractive index. The surface-area and volume concentrations follow from the particle number size distribution $n(r)$ after multiplication with $4 \pi r^{2}$ and $4 \pi r^{3} / 3$, respectively. The surface-weighted (effective) mean radius is calculated as

$r_{\text {eff }}=\frac{\int n(r) r^{3} \mathrm{~d} r}{\int n(r) r^{2} \mathrm{~d} r}$

and used as a measure of mean particle size. Finally, the singlescattering albedo at $532 \mathrm{~nm}$ is calculated from the retrieved parameters by means of Mie calculations (Bohren and Huffman, 1983).

To get a final inversion result as shown in this paper, six individual inversion runs were performed and analysed: one with the original $3+2$ data set retrieved through aerosol-type separation and additional five with up to $20 \%$ of random noise added to the input data (see also Tesche et al., 2008). The inversion of the five noisy data sets provides insight in the possible spread of results for slight variations in the input parameters (i.e. retrieval errors) and furthermore gives an indication of the general reliability of the input data set. This approach is considered to represent a sensitivity study for each inversion data set. The procedure of inversion and subsequent analysis of one original and five noisy data sets leads to two error bars for the results presented in Section 4: one is the mean of the standard deviation of the six inversion runs for one height level and the other is the standard deviation of the mean of the six individual mean values.

\section{Observations and results}

Table 1 lists the days of the SAMUM-2 measurements in January and February of 2008 to which the aerosol-type 
Table 1. SAMUM-2a measurement days and times that were chosen for aerosol-type separation and subsequent inversion of the optical data sets for biomass-burning smoke. Not every inversion led to reasonable results even though the optical input data seemed adequate. The last two columns give the times of airborne in situ measurements in the vicinity of the lidar site together with the measured in situ SSAs.

\begin{tabular}{lcccccc}
\hline Day of 2008 & $\begin{array}{c}\text { Measurement time } \\
\text { lidar (UTC) }\end{array}$ & $\begin{array}{c}\text { Height range } \\
(\mathrm{m})\end{array}$ & $\begin{array}{c}\text { Range of } r_{\text {eff }} \\
(\mu \mathrm{m})\end{array}$ & $\begin{array}{c}\text { Range of SSA } \\
\text { (inversion) }\end{array}$ & $\begin{array}{c}\text { Measurement time } \\
\text { in situ (UTC) }\end{array}$ & $\begin{array}{c}\text { Range of SSA } \\
\text { (in situ) }\end{array}$ \\
\hline 22 January & $2020-2230$ & $1620-2820$ & $0.23-0.29$ & $0.66-0.84$ & $1630-1645$ & $0.71-0.78$ \\
23 January & $2040-2240$ & $1020-2820$ & $0.16-0.35$ & $0.73-0.86$ & $1630-1830$ & $0.71-0.80$ \\
26 January & $0130-0230$ & $1620-2820$ & $0.12-0.28$ & $0.68-0.89$ & - & - \\
31 January & $2132-2232$ & $1620-4620$ & $0.10-0.32$ & $0.65-0.89$ & - & - \\
3 February & $2038-2220$ & $2220-4920$ & $0.16-0.36$ & $0.63-0.85$ & - & - \\
5 February & $2038-2252$ & $2820-4020$ & $0.13-0.16$ & $0.73-0.82$ & $1630-1830$ & 0.79 \\
6 February & $2010-2235$ & $3120-4320$ & $0.26-0.35$ & $0.64-0.76$ & $1530-1705$ & $0.76-0.82$ \\
\hline
\end{tabular}

separation was applied to. The requirement for an absence of low- and mid-level clouds restricted the investigation to seven days. Also given in the table are the height ranges to which the separation could be applied to and the ranges of obtained effective radii and SSA. The last column of Table 1 gives the times of Falcon overflights in the vicinity of the lidar site which enabled a comparison of the findings of the inversion calculations and the results of airborne in situ measurements.

Profiles of dust concentration as predicted/analysed with the Dust REgional Atmospheric Model (DREAM ${ }^{1}$, Nickovic et al., 2001; Pérez et al., 2006a, b; Haustein et al., 2009) give a good impression about the vertical distribution of mineral dust in the atmospheric column over the measurement site. The corresponding profiles closest to the measurements discussed in this paper (Table 1) are shown in Fig. 2 . The DREAM profiles support that large amounts of mineral dust contributed to the optical properties measured with our lidar systems at Cape Verde. A noticeable peak at $1 \mathrm{~km}$ height describes the layer of pure dust close to the surface (see the SAMUM-2 overview given by Knippertz et al. (2011) and the discussions by Tesche et al., 2011). However, dust is also present at larger heights. This is in agreement with the large particle depolarization ratios observed in these elevated layers (Groß et al., 2011a; Tesche et al., 2011). The top of the dust layers in Fig. 2 generally shows good agreement with the height of the observed aerosol layers (Fig. 1 in Knippertz et al., 2011).

\subsection{January 2008}

Two case studies are discussed before we summarize the findings in Section 4.3. The lidar measurement in the evening of 22 January 2008 (including an overview picture similar to Fig. 5 in this paper) is discussed in detail by Tesche et al. (2011). In addition to the trajectories presented by Knippertz et al.

\footnotetext{
${ }^{1}$ http://www.bsc.es/projects/earthscience/DREAM
}

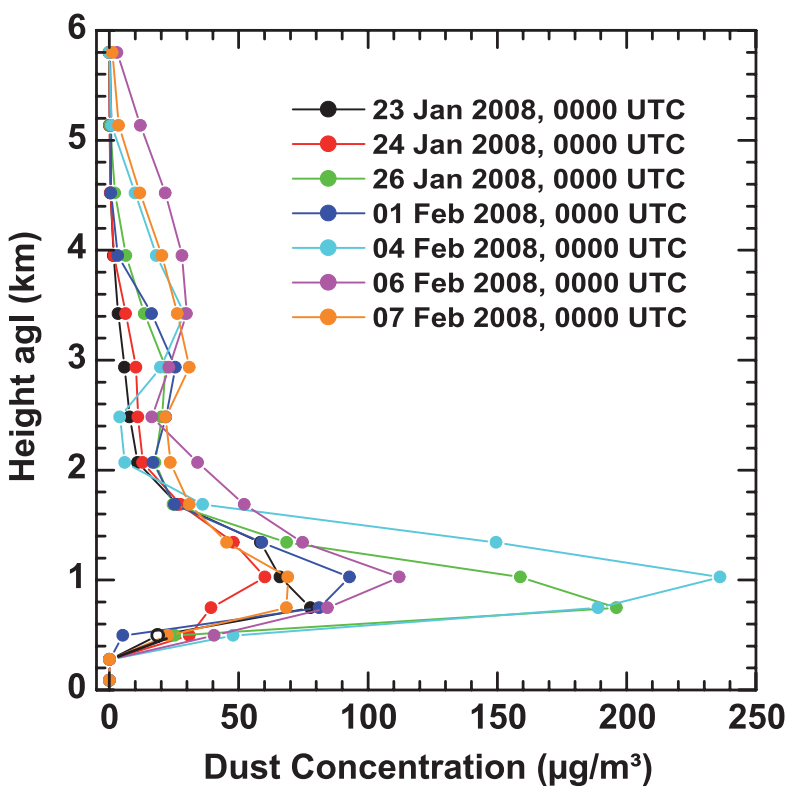

Fig. 2. DREAM height profiles of dust concentration for times closest to the measurements presented in Table 1 . The peak at $1 \mathrm{~km}$ height describes the pure dust layer close to the surface (see Fig. 1a in Knippertz et al., 2011). Dust is also present at larger heights. Thus, its contribution needs to be subtracted from the measured optical profiles to obtain a data set suitable for inversion.

(2011), we carefully examined HYSPLIT ${ }^{2}$ backward trajectories (Draxler and Rolph, 2010) to investigate the origin of the observed aerosol layers. 10-day backward trajectories arriving over the measurement site at 21 UTC on 22 January 2008 in height intervals of $500 \mathrm{~m}$ are shown in Fig. 3. The trajectories show similar patterns at almost every height range. They show that the air adveted to Cape Verde spent a considerable period of time over the red biomass-burning area in Fig. 3a that represents MODIS fire counts ${ }^{3}$ between 11 and 20 January 2008. The area is

\footnotetext{
${ }^{2}$ http://ready.arl.noaa.gov/HYSPLIT.php

${ }^{3}$ http://rapidfire.sci.gsfc.nasa.gov/firemaps/
} 

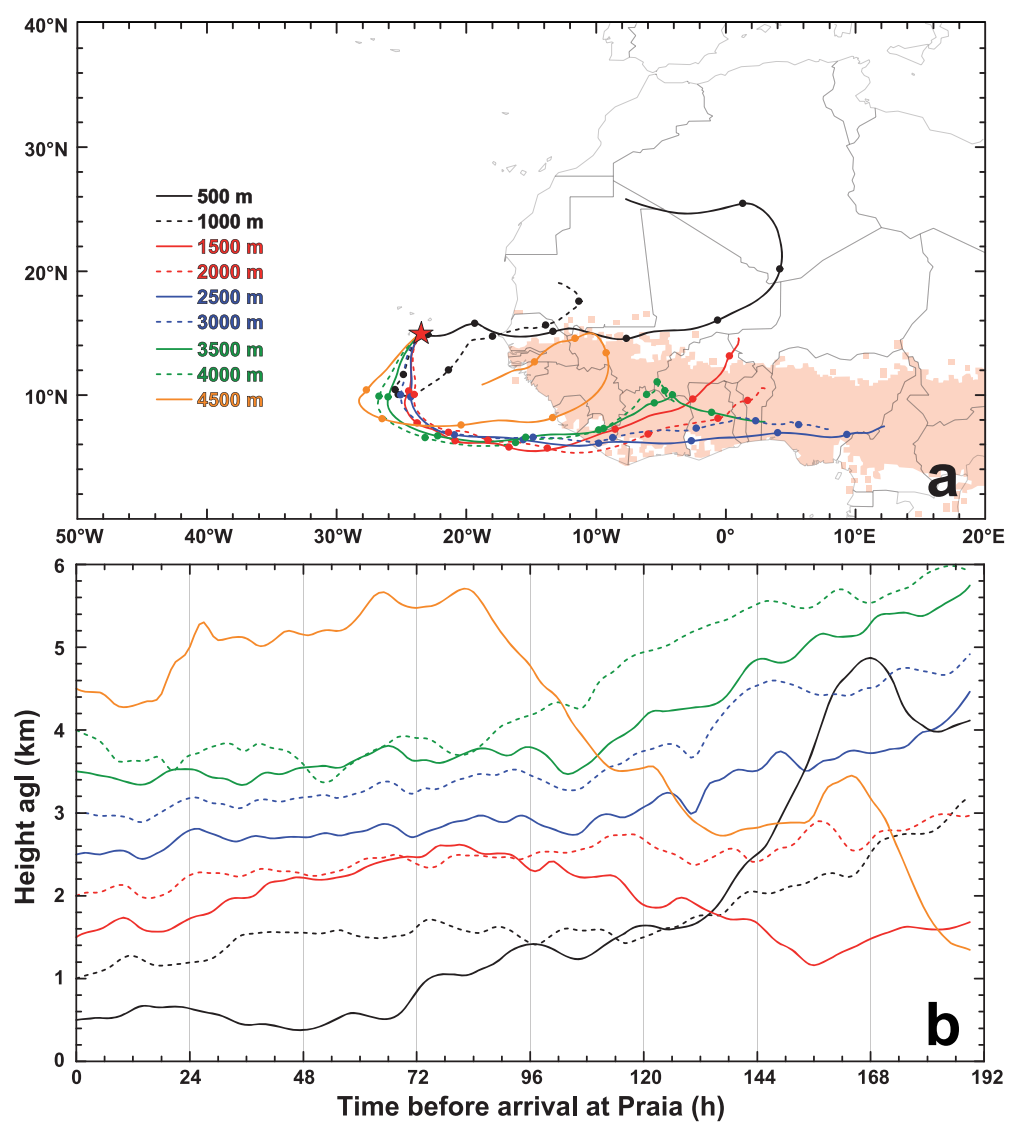

Fig. 3. Ten-day HYSPLIT backward trajectories ending over Praia at 2100 UTC on 22 January 2008. The location (a) and height (b) of air parcels arriving over Praia at various heights between 0.5 and $4.5 \mathrm{~km}$ is illustrated by different colours and styles of the respective lines. Saharan dust is present at 0.5 (black, solid) and $1.0 \mathrm{~km}$ height (black, dashed). Above $1.0 \mathrm{~km}$ height air is advected to Praia from the red areas of active fires detected by MODIS between 11 and 20 January 2008. representative for winter conditions (Barbosa et al., 1999; Cooke et al., 2008). Only air parcels arriving at the lowermost levels of $0.5 \mathrm{~km}$ (solid black line) and $1.0 \mathrm{~km}$ (dashed black line) travelled at lower heights and crossed areas in Algeria, Mali, and Mauritania where significant dust uptake might occur.

Figure 4 shows profiles ( $660 \mathrm{~m}$ vertical smoothing window) of the lidar measurement at 2005-2100 UTC on 22 January 2008. In contrast to Fig. 7 in Tesche et al. (2011), only BERTHA measurements are shown, except for the 532-nm depolarization-ratio profiles (Fig. 4e) which were obtained with MULIS (see Section 2.1). Figure $4 \mathrm{f}$ gives the contributions of dust (red) and smoke (green) to the measured total backscatter (solid) and extinction (dashed) coefficient at $532 \mathrm{~nm}$ shown in (a) and (b), respectively. Dust and smoke contribute almost equally to the 532-nm backscatter coefficient, whereas the corresponding extinction coefficient is dominated by smoke aerosol with contributions of $60-70 \%$. As expected from the pattern of the backward trajectories in Fig. 3 the mixture of dust and smoke shows little variation with height.

The lower panel of Fig. 4 shows the complete lidar data set for the pure biomass-burning smoke (lines in $\mathrm{g}-\mathrm{j}$ ) together with the $3+2$ data sets that were used as input for the inversion algorithm (circles in $\mathrm{g}$ and $\mathrm{h}$ ) and the retrieved microphysical properties ( $\mathrm{k}$ and $\mathrm{l}$ ). Due to the smaller size and higher absorption of the pure biomass-burning smoke, lidar ratios (i) and Ångström exponents (j) are increased compared to the ones of the dust/smoke mixture which are shown in the upper panel. The retrieved effective radii vary between 0.23 and $0.29 \mu \mathrm{m}$ (see also Table 1 ). Values of the single-scattering albedo decrease from 0.84 to 0.66 with height and indicate more absorbing aerosol at higher levels. The error bars of these two parameters were obtained from the general spread of the results of six individual inversion runs for each height level (Section 3.2). The combination of the two errors gives an impression of the uncertainty of individual measurements (red bars) and of the general uncertainty of an inversion result (black bars). In case of the single-scattering albedo, errors of individual inversion results are rather low (red bar) whereas the spread of inversion results is relatively large (black bar). For the effective radius, even individual results can show a rather large uncertainty. In the case of 22 January 2008 the uncertainty of the effective radius and the SSA increase with height. Results of airborne in situ measurements of the effective radius are shown for the fine mode $(r<0.5 \mu \mathrm{m})$ and for the entire particle size distribution (Fig. 4k). Figure 41 also shows in situ findings of the SSA that are assumed to represent biomass-burning smoke conditions. These values are similar to the findings of the inversion calculations. The good agreement of the values at about $1.7 \mathrm{~km}$ height, the low contribution of 

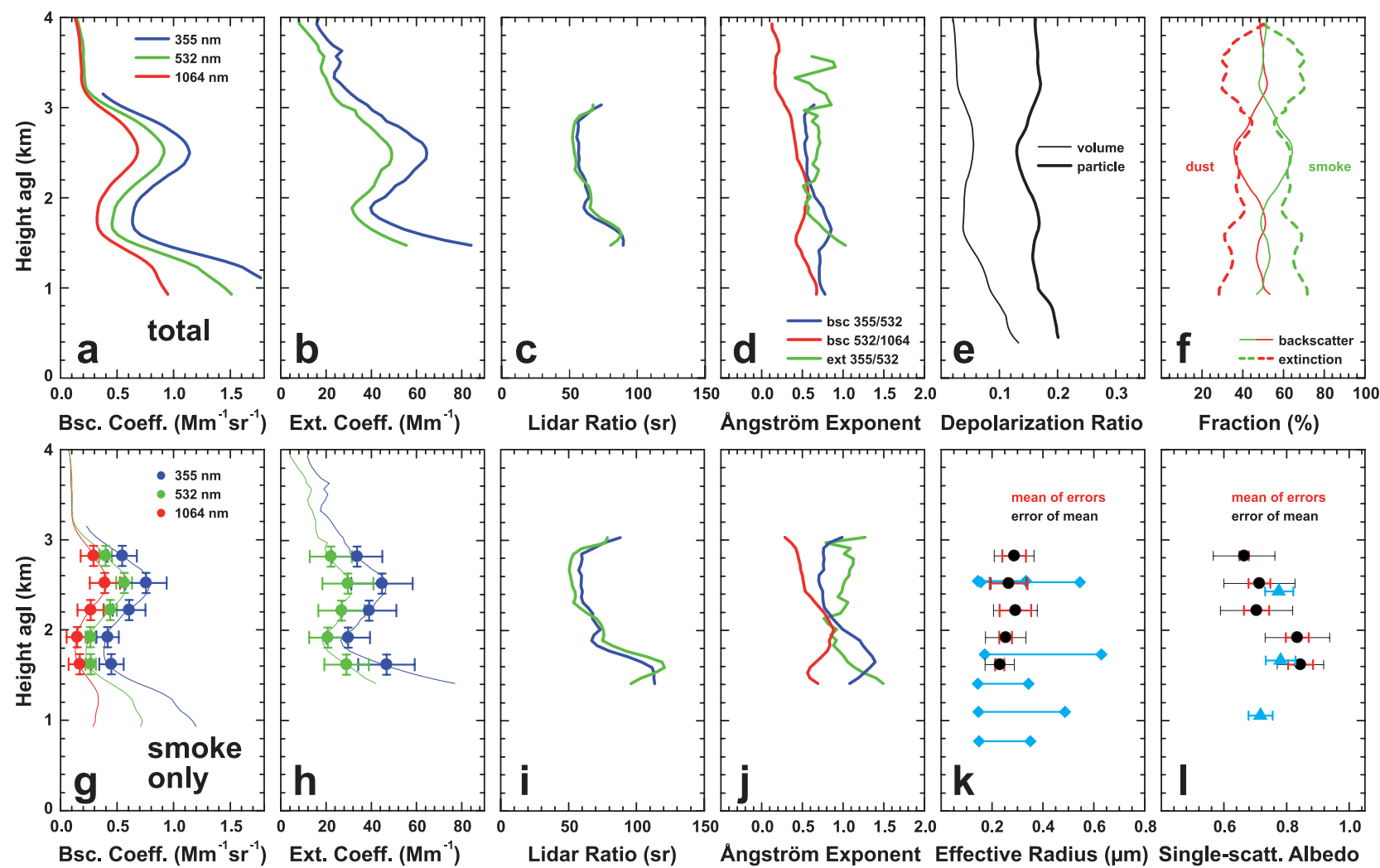

Fraction (\%)

Fig. 4. Evening measurement of 22 January 2008, 2005-2100 UTC. Profiles of total backscatter (a) and extinction coefficients (b), the respective lidar ratios (c) and Ångström exponents are measured with BERTHA. The profiles of the volume and particle depolarization ratio (e) at $532 \mathrm{~nm}$ are measured with MULIS. The relative contribution of dust and smoke (f) to the measured coefficients of backscatter (solid lines) and extinction (dashed lines) is used to obtain profiles of backscatter (g), extinction (h), lidar ratio (i), and Ångström exponents (j) for pure biomass-burning smoke. Inversion of the latter profiles results in values of the effective radius (k) and 532-nm single-scattering albedo (l) of the smoke particles. Red error bars in (k) and (l) denote the mean value of the individual errors of the six inversion runs. Black bars represent the standard deviation of the mean of the individual mean inversion results. Left and right blue diamonds in $(\mathrm{k})$ indicate the effective radius of the fine mode (particle radius smaller than $0.5 \mu \mathrm{m}$ ) and of the total particle size distribution, respectively, as derived from airborne in situ measurements. The horizontal bar connecting the diamonds illustrates the potential range of effective radii of the smoke particles. Blue triangles in (1) denote the results of in situ measurements of the SSA.

dust to the extinction coefficient below $2 \mathrm{~km}$ height (Fig. 4f), and the low SSA from in situ measurements at lower heights (blue triangle at $1057 \mathrm{~m}$ height) indicate that the contribution of dust to the total aerosol was comparably low in the lowermost $2 \mathrm{~km}$ above ground level. At $2427 \mathrm{~m}$ height, the result of the in situ measurement shows a larger SSA because of the larger contribution of dust to the aerosol mixture. The effective radii of total size distributions for observations that are assumed to represent smoke conditions are generally larger than the inversion results for pure smoke. Much better agreement between inversion and in situ measurement is found, if only the fine mode of the measured size distribution is considered to represent biomassburning smoke. A discussion of this difference is given in Section 4.3. Heights below $1.5 \mathrm{~km}$ could not be covered by lidar due to the overlap effect of BERTHA (Tesche et al., 2009a, 2011).

\subsection{February 2008}

The observations on 3 February 2008 are representative for the second part of the SAMUM-2 winter measurements (Knippertz et al., 2011). During this period, we usually observed a maritime boundary layer in the lowermost $0.5-1.0 \mathrm{~km}$ that was topped by a shallow dust layer. At larger heights, we always observed layers of a mixture of Saharan dust and biomass-burning smoke from southern West Africa. Linear particle depolarization ratios of 0.1-0.2 within this elevated plume (Groß et al., 2011a) are much too high to be caused by pure smoke aerosol. The depolarization ratio of biomass-burning smoke is in the range of $0.05 \pm 0.02$ as is discussed by Tesche et al. (2009b). Some days later in February the lower pure dust layer vanished and only the elevated mixed layer remained (Knippertz et al., 2011).

Similar to the cases discussed in Tesche et al. (2011), Fig. 5 gives an overview of the observations on 3 February 2008. Sun 


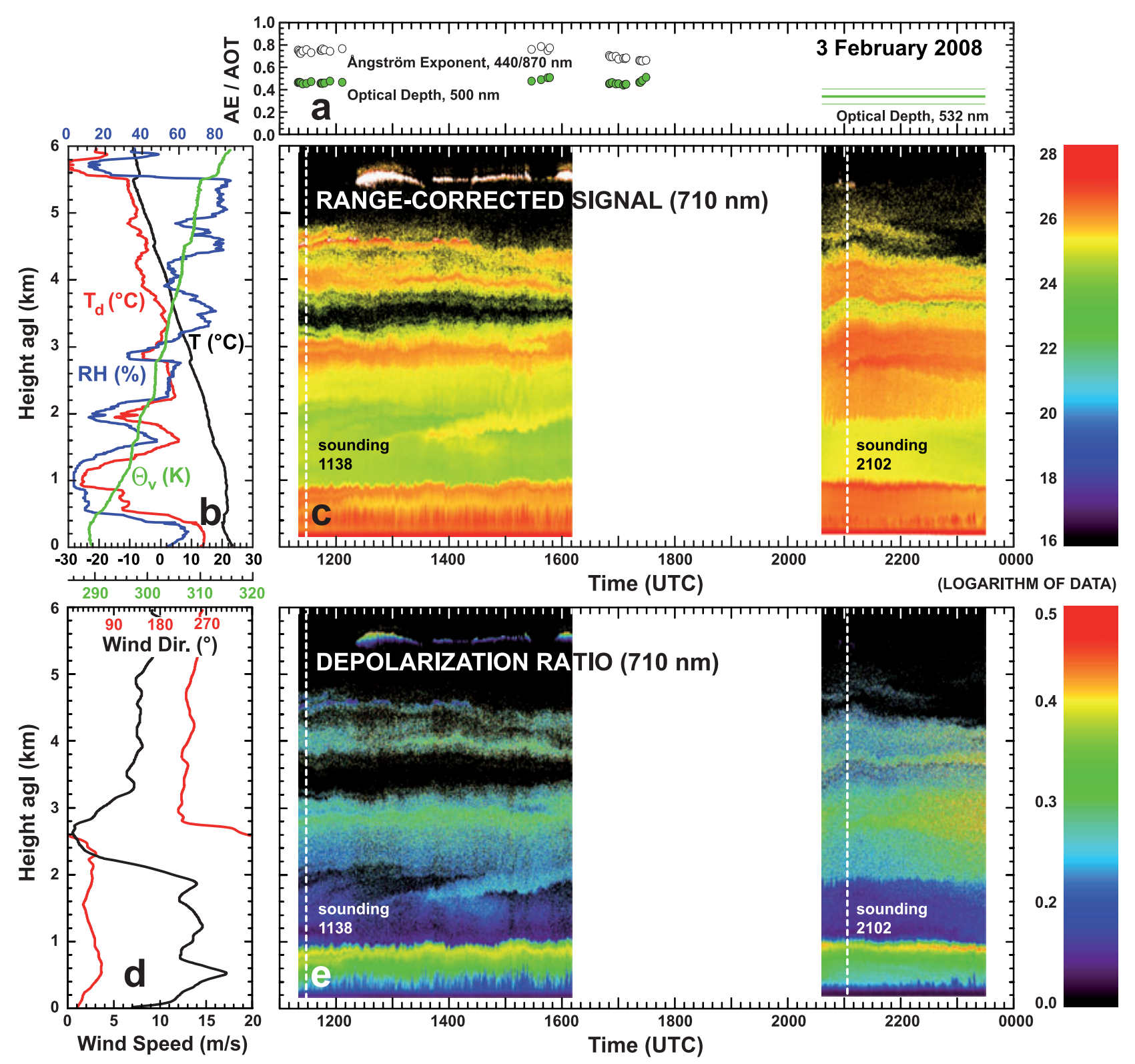

Fig. 5. Measurement of 3 February 2008, 1120-2329 UTC. Sun photometer measurements (a) of optical depth at 500 nm and the 440/870-nm Ångström exponent are shown as green and white dots, respectively. The evolution of the aerosol layer in terms of the range-corrected signal (c) and the linear depolarization ratio (e) is displayed together with profiles of a radiosonde (b and d) launched at $1138 \mathrm{UTC}$ (left dotted line in $\mathrm{c}$ and e). The nighttime measurement was performed from 2038 to 2329 UTC (after the gap in c and e). The 532-nm optical depth of this measurement is shown as a bold horizontal line in (a). Thin green lines mark the range of possible values, if a maximum uncertainty of $20 \%$ is considered in the integration of the lidar-derived extinction profile (see Tesche et al., 2011). The profiles measured with BERTHA (backscatter, extinction, lidar ratio, and Ångström exponents) and MULIS (depolarization ratio) are shown in the upper panel in Fig. 7.

photometer measurements (Toledano et al., 2011) are shown in the uppermost panel. An optical depth of 0.5 was observed at $500 \mathrm{~nm}$ during the day. The respective 440/870-nm Ångström exponents are in the range of $0.6-0.8$. These column-integrated values indicate the presence of large mineral dust particles in the otherwise smoke-dominated aerosol plume. Pure biomassburning smoke would show Ångström exponents well above unity (Eck et al., 1999, 2003). Time-height displays of the rangecorrected signal (c) and the volume depolarization ratio (e) measured with BERTHA at $710 \mathrm{~nm}$ show that several aerosol layers were present up to $5 \mathrm{~km}$ height. The depolarization ratio shows low values (blue and purple) in layers with low contribution of mineral dust, e.g. the maritime boundary layer which stretches from the surface to about $500 \mathrm{~m}$ height and the layer of low 
aerosol load located between 1 and $2 \mathrm{~km}$ height. Black areas denote aerosol free height ranges. A thin mineral dust layer is visible in (e) at about $1 \mathrm{~km}$ height. Between 2 and $5 \mathrm{~km}$ height, a mixture of mineral dust and biomass-burning smoke is present. Soundings were performed at 1138 and 2102 UTC (shown as vertical dotted lines in the lidar plots). The meteorological profiles of the morning sounding are shown in (b) and (d). The different aerosol layers can also be identified in the profiles of temperature $(\mathrm{T}$, red), relative humidity $(\mathrm{RH}$, blue), and virtual potential temperature $\left(\Theta_{v}\right.$, green). A strong shift in wind direction (red) from easterly direction below $2.5 \mathrm{~km}$ height to westerly direction above is accompanied by a change in wind speed (black). Almost no wind is observed at the top of the dry layer of low aerosol load (at about $2.5 \mathrm{~km}$ height). The optical depth of the evening lidar measurement from 2038 to 2220 UTC is shown as a horizontal green line in (a). Optical depth decreased from 0.50 at $500 \mathrm{~nm}$ during the day (Sun photometer measurement) to 0.35 at $532 \mathrm{~nm}$ after sunset (lidar measurement).

The 10-day backward trajectories arriving over Praia at 2200 UTC on 3 February 2008 (Fig. 6) are combined with a map of the area of active fires observed by MODIS between 31 January and 9 February 2008. In contrast to the evening of 22 January 2008 (Fig. 3), the trajectories in Fig. 6 cover a much wider area and suggest more complex aerosol conditions compared to the first case study. This is also evident from the lidar measurements shown in Fig. 5. The air parcels arriving at 0.5 and $1.0 \mathrm{~km}$ height (solid and dashed black lines) represent the dust layer close to the surface (Fig. 5). They passed over the source regions of mineral dust in Algeria, Mali, and Mauritania during the last seven days before arrival and show no contact to the red area of biomass-burning activity. The relatively clean region between 1 and $2 \mathrm{~km}$ height in Fig. 5 corresponds to the solid red trajectory that represents air arriving at $1.5 \mathrm{~km}$ height. It originates over the northern Atlantic and shows no contact to continental Africa and the respective sources of aerosols. The air parcels that arrive within the mixed dust/smoke layer between 2 and $4 \mathrm{~km}$ height (red dashed, blue solid and dashed, green solid and dashed) crossed dust and smoke sources (2.0 and $2.5 \mathrm{~km}$ height) or spent all ten days before arrival at Praia over the red biomassburning area. Above $4 \mathrm{~km}$ height, air is quickly advected to Cape Verde from the tropical Atlantic (trajectories not shown). This corresponds to the clean troposphere above the African aerosol layers (Knippertz et al., 2011).

Figure 7 shows the profiles (660 m vertical smoothing window) of the evening measurement at 2038-2220 UTC on 3 February 2008. Compared to the measurement on 22 January 2008 we find much higher backscatter and extinction coefficients for the total aerosol. Lidar ratios vary between 60 and $80 \mathrm{sr}$
Fig. 6. Same as Fig. 3 but for backward trajectories ending over Praia at 2200 UTC on 3 February 2008.
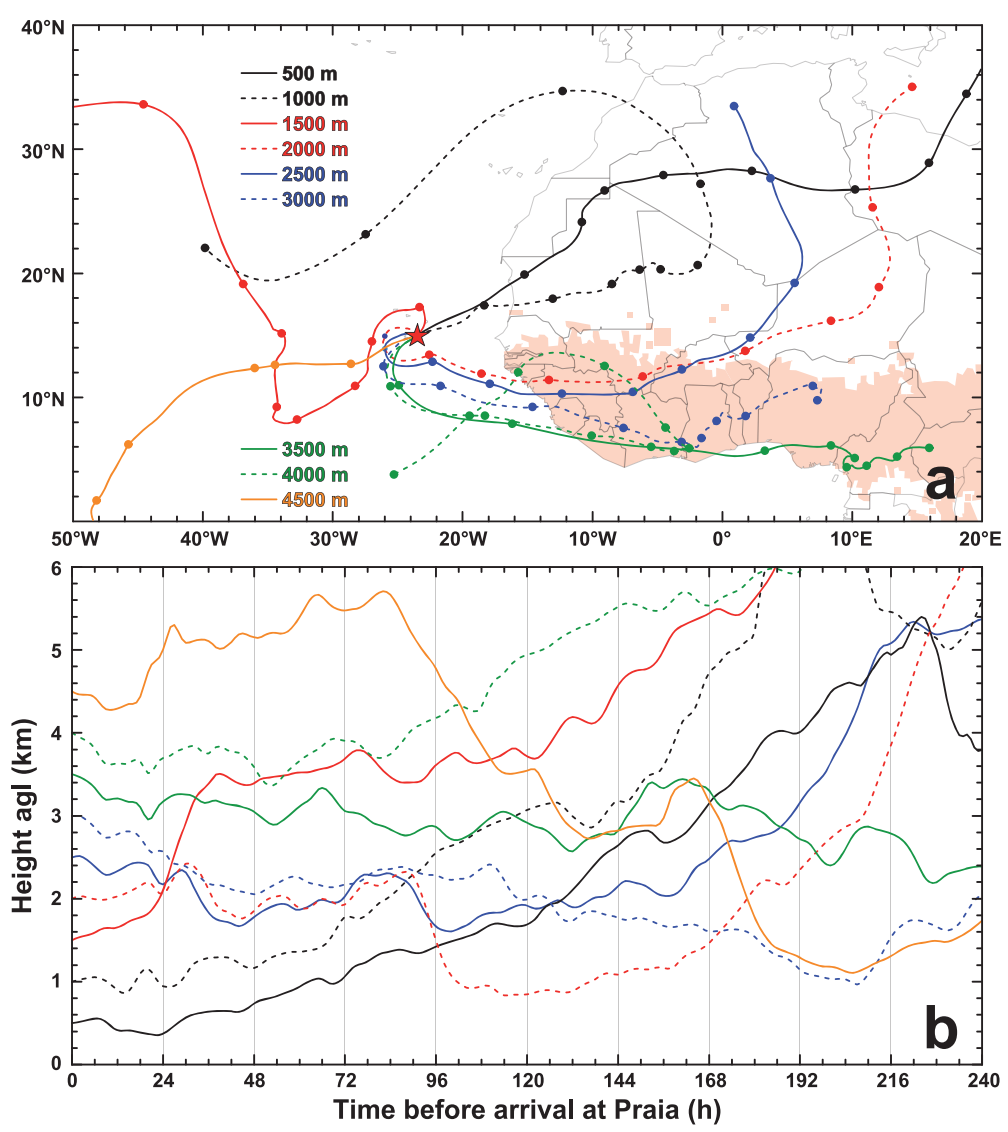

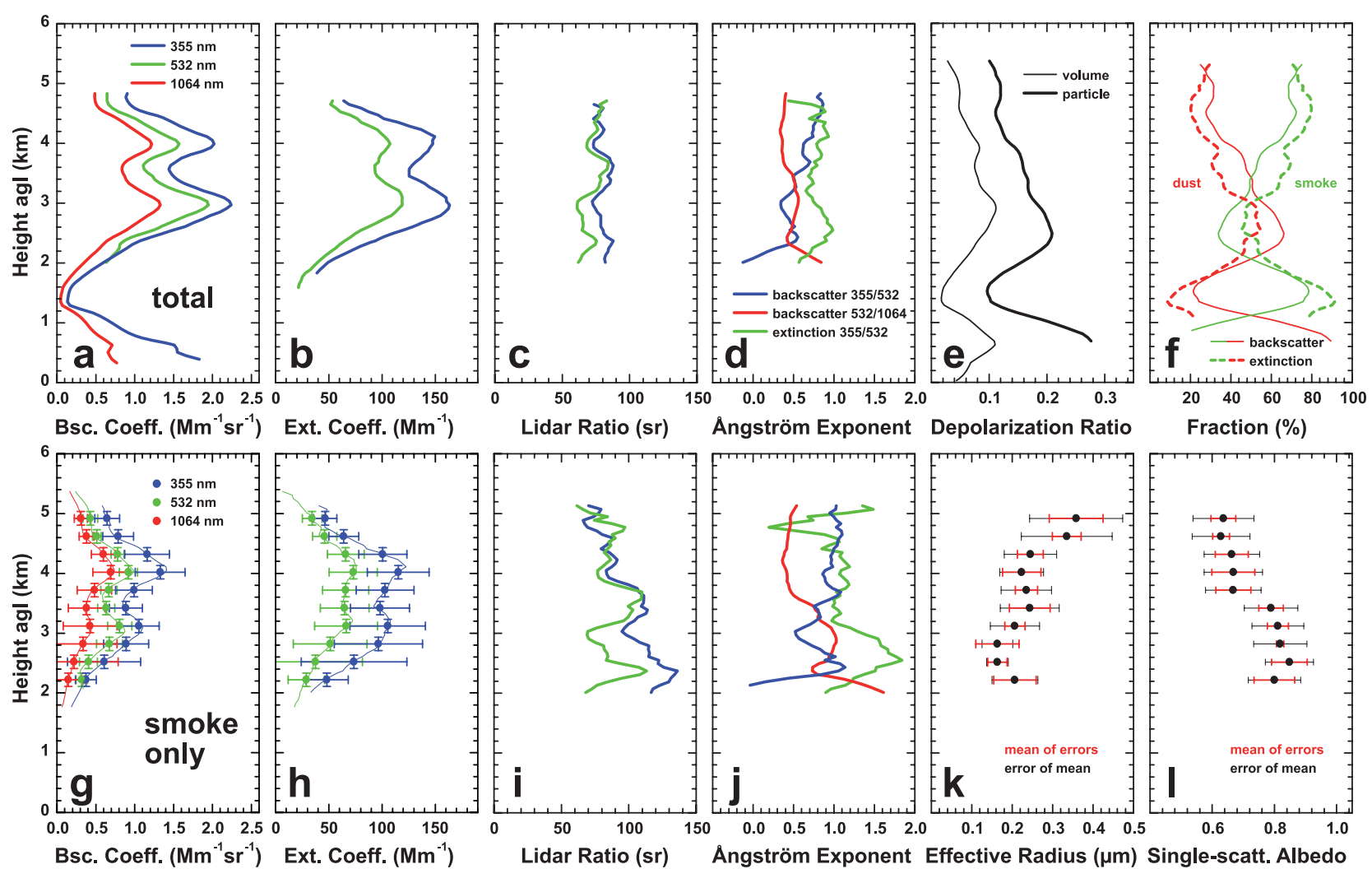

Fig. 7. Same as Fig. 4 but for the evening measurement of 3 February 2008, 2038-2220 UTC.

and Ångström exponents are between 0.4 and 1.0. These values already indicate a significant contribution of biomass-burning smoke to the measured total signal. The particle depolarization ratio profile shows the highest contribution of dust at $2-3 \mathrm{~km}$ height: $70 \%$ to the $532-\mathrm{nm}$ backscatter coefficient and $60 \%$ to the 532-nm extinction coefficient. In the elevated aerosol layer between 2 and $5 \mathrm{~km}$ height, the dust contribution to the total measured 532-nm backscatter and extinction coefficients decreases to $30 \%$ and $20 \%$, respectively. The inferred pure-smoke lidar ratios of 80-110 sr are much higher than the ones for the dust/smoke mixture. This indicates higher absorption and suggests low values of SSA of smoke. Smoke Ångström exponents are also increased with respect to the aerosol mixture. The higher values at lower heights furthermore suggest smaller particles in this region. The results of the inversion are in agreement with this assumption. We inferred rather small effective radii below $0.2 \mu \mathrm{m}$ in the range from 2 to $3 \mathrm{~km}$ height where smoke lidar ratios show values of up to $130 \mathrm{sr}$. The particles in this height range show SSA values of around 0.8. In the upper height range from 3.5 to $5.0 \mathrm{~km}$ we derived smoke lidar ratios of $90 \mathrm{sr}$ at both 355 and $532 \mathrm{~nm}$. Even though these values are lower than the ones in the lower height region (which would suggest an increase in SSA), we retrieved very low SSA values of around 0.64-0.68. This decrease of SSA with height comes along with an increase of particle effective radius with values between 0.20 and $0.35 \mu \mathrm{m}$. Particle size also has an influence on the lidar ratio. Generally, an increase in particle size leads to a decrease of the lidar ratio. The lowest SSA was inferred at the highest levels together with the largest effective radii.

\subsection{Further results}

The profiles of the extinction coefficients at 355 (blue) and $532 \mathrm{~nm}$ (green), the contribution of dust and smoke to the measured backscatter and extinction coefficients, the effective radius, and the single-scattering albedo for the remaining days listed in Table 1 (except for 31 January 2008 which is already discussed in Tesche et al., 2009b) are shown in Fig. 8 together with the findings of the in situ measurements of the smoke effective radius (for the fine mode with radii smaller than $0.5 \mu \mathrm{m}$ and the total particle size distribution, blue diamonds) and the SSA (blue triangles) aboard the Falcon. On 23 January 2008 we observed a mixed dust/smoke layer up to about $3 \mathrm{~km}$ height. In the upper part of the plume we observed low values of the extinction coefficient (which were mostly due to smoke). As a consequence the effective radius at the $2.8-\mathrm{km}$ level was inferred with high uncertainty. In the lower part of the aerosol layer effective smoke radii of about $0.2 \mu \mathrm{m}$ were retrieved together with values of the SSA between 0.80 and 0.85 . The results of the airborne in situ measurements on 23 January 2008 generally agree with the 

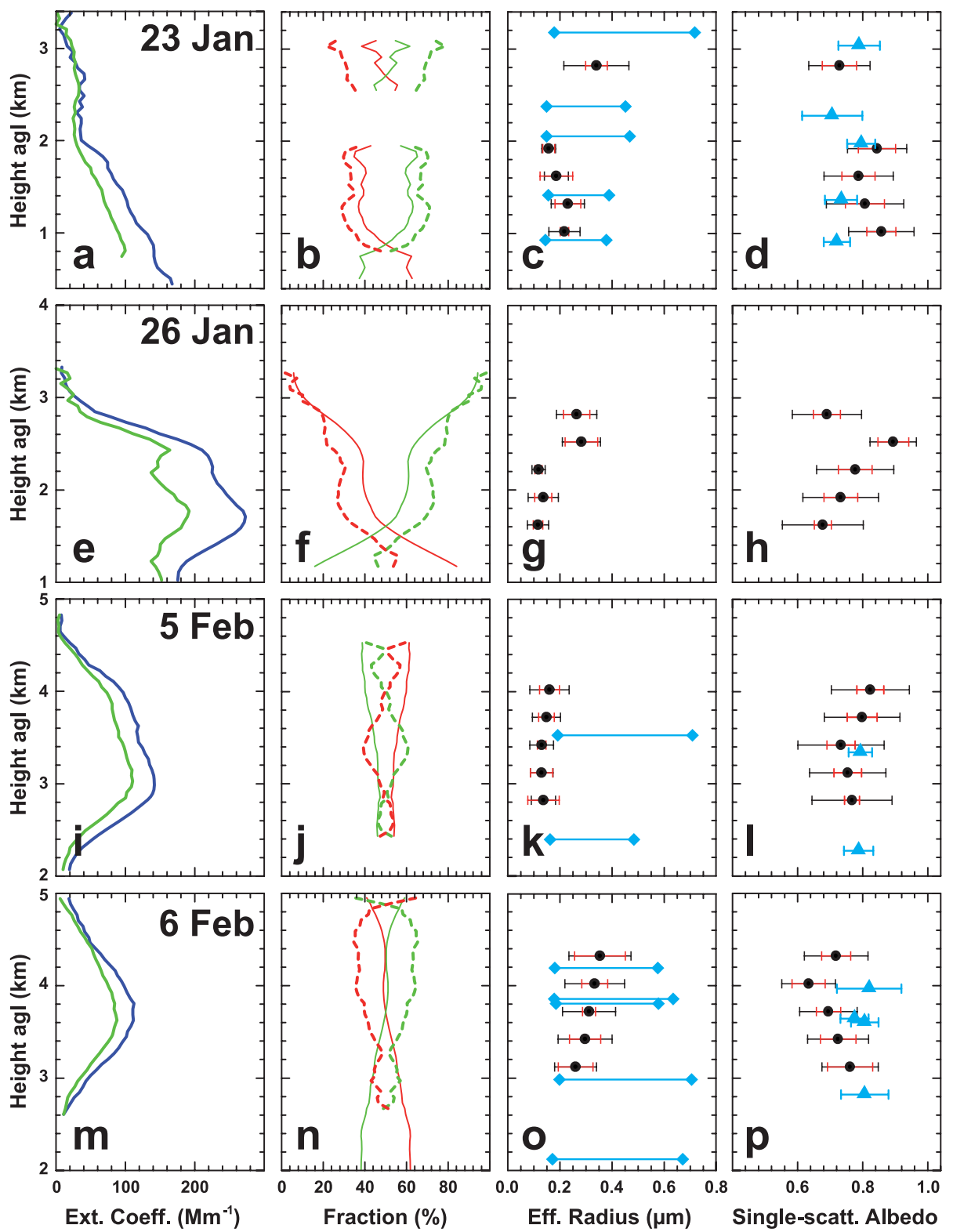

Fig. 8. Same as Fig. 4b, f, k, and 1 but for the evening measurements of 23 January 2008, 2040-2240 UTC (a-d), 26 January 2008, 0130-0230 UTC (e-h), 5 February 2008, 2038-2252 UTC (i-l), and 6 February 2008, 2010-2235 UTC (m-p).

inversion results. Smoke aerosol can be allocated to the fine mode of the particle size distribution. The in situ SSAs show slightly smaller values than the inversion results. Such differences might be caused by the different measurements times (in situ measurements during the afternoon and lidar measurements during the night, see Table 1) and inhomogeneous aerosol conditions over the measurement site.

For 26 January 2008 which is the day with the largest extinction coefficients presented in this study we retrieved smoke contributions of $60-100 \%$ to the backscatter and extinction coefficients at $532 \mathrm{~nm}$. In the lower part of the aerosol layer we retrieved very small effective radii together with small
SSA. For the days presented so far, we usually observed the lower SSA values for larger effective radii. The dominance of smoke aerosol increases with height and leads to very low SSA of 0.66 retrieved for the $2.8-\mathrm{km}$ height level. The measurements of 25-26 January 2008 are also discussed in detail by Ansmann et al. (2011), Engelmann et al. (2011), and Lieke et al. (2011).

Similar extinction profiles were observed on 5 and 6 February 2008. However, mineral dust showed a larger impact during the first day. For 5 February 2008 we inferred effective radii of $0.10-0.15 \mu \mathrm{m}$ and SSA values of $0.72-0.80$. Larger effective radii of $0.25-0.30 \mu \mathrm{m}$ and lower values of the SSA of 

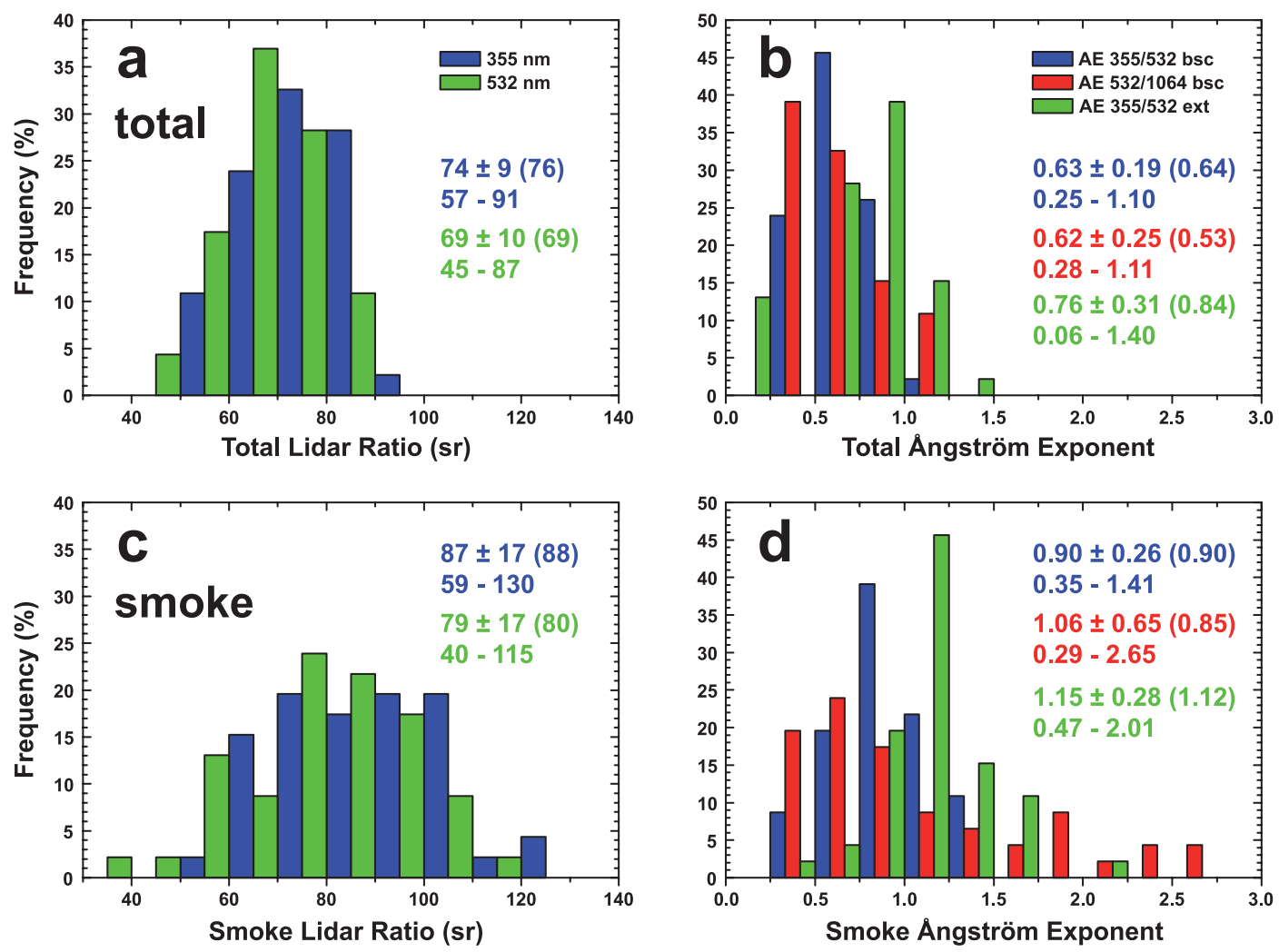

Fig. 9. Frequency distributions of total (dust+smoke, upper panel) and pure smoke (lower panel) lidar ratios (left) and Ångström exponents (right) for the 46 inversion levels (see Table 1). Numbers in the plots indicate mean, median, standard deviation, and total range of the respective distribution.

$0.60-0.76$ were found for 6 February 2008 . The results of the in situ observations confirm the low SSA derived from the inversion calculations. Note that the in situ observations refer to the aerosol mixture while the inversion results are representative for pure biomass-burning smoke and can thus be smaller than the measured values (see Fig. 8p). As in case of 23 January 2008, differences might also be caused by the lag in the observations and associated changing aerosol conditions.

All comparisons of measured smoke effective radius and the one inferred from the lidar measurements show a large disagreement of a factor of about two. Effective radii calculated from that part of the in situ size distributions which is assumed to be constituted by smoke particles were $0.52 \pm 0.16 \mu \mathrm{m}$ on the four comparison days (see Table 1). Note that no separation of the contributions of mineral dust and biomass-burning smoke to the total size distribution is possible for the in situ measurements. The general approach is to assume that mineral dust comprises the coarse mode of the size distribution while smoke particles constitute the smaller fine and accumulation modes. Even though small dust particles might be included in the retrieval of the complex refractive index and the SSA, the findings inferred from the in situ observations are in surprisingly good agreement with the inversion results (Table 1). However, the latter show a much larger spread of the derived values.

\section{General findings and discussion}

Frequency distributions of lidar ratios and Ångström exponents for the measured total aerosol (upper panel) and the pure biomass-burning smoke (lower panel) are shown in Fig. 9. The histograms contain the optical properties of the 46 height levels for which input parameters and inversion results are assumed to be reliable (Table 1). The mean values of the total lidar ratios and Ångström exponents for the seven days are in agreement with the mean values of the SAMUM-2 winter campaign presented in Fig. 12 of Tesche et al. (2011). Compared to the values for the total aerosol, mean smoke lidar ratios of $87 \pm 17 \mathrm{sr}$ at $355 \mathrm{~nm}$ and $79 \pm 17 \mathrm{sr}$ at $532 \mathrm{~nm}$ as retrieved by aerosol-type separation are increased and also show a larger spread of values. Considering a dust fraction of $40-60 \%$ and a dust lidar ratio of $55 \mathrm{sr}$ as observed during SAMUM-1 (Tesche et al., 2009a), the lidar ratio of pure biomass-burning smoke has to be in the range of 75-85 sr to result in the values of $67 \mathrm{sr}$ at 355 and 532 $\mathrm{nm}$ that were observed within the mixed dust/smoke plume over Praia (Tesche et al., 2011). Such values of the smoke lidar ratio are in agreement with observations during DABEX (Heese and Wiegner, 2008) and other studies of African biomass-burning smoke that, in some cases, estimated even higher values of 90-130 sr (Campbell et al., 2003; Pelon et al., 2008) from elastic backscatter lidar measurements. Elevated plumes of combustion 
smoke were observed with Raman lidar at the Maldives during INDOEX. Ansmann et al. (2000) and Franke et al. (2001, 2003) found 532-nm lidar ratios of 60-90 sr within air masses that crossed the central eastern parts of India before being advected to the measurement site. Biofuel combustion is dominant in this region.

Mean values of backscatter- and extinction-related Ångström exponents for pure smoke (Fig. 9d) are in the range of 0.90-1.15. Even though individual values cover the range from 0.29 to 2.65 , median values are in good agreement with the mean values. The derived mean values represent an increase by up to $50 \%$ compared to the respective mean values for the dust/smoke mixture shown in Fig. 9b. The increase is in agreement with the fact that pure smoke particles are smaller and more light absorbing at visible wavelengths than mineral dust or a mixture of dust and smoke (Eck et al., 1999). The values also agree with the observations of INDOEX where Ångström exponents of 0.8-1.4 were found within plumes of North Indian pollution (Franke et al., 2003).

Figure 10 shows frequency distributions of the effective radius, the single-scattering albedo, and the real and imaginary part of the refractive index for the 46 data sets (height levels, see
Table 1). From the inversion we retrieved effective radii between 0.10 and $0.36 \mu \mathrm{m}$ with a mean value of $0.22 \pm 0.08 \mu \mathrm{m}$. This range of numbers is in agreement with inversion results of lidar observations of long-range transport of urban haze and biomassburning aerosol during INDOEX (Ansmann et al., 2000; Müller et al., 2000b, 2003), of layers of biomass-burning aerosol during LACE 98 (Wandinger et al., 2002), and of southeast Asian aerosol during PRIDE-PRD (Tesche et al., 2008). These investigations resulted in effective radii between 0.10 and $0.35 \mu \mathrm{m}$. The mean 532-nm smoke SSA was found to be $0.75 \pm 0.07$. Individual solutions varied between 0.63 and 0.89 . Inversions of the lidar observations during INDOEX resulted in 532-nm SSA values between 0.75 and 0.90 . The mean real and imaginary parts of the refractive index were found to be in the range of 1.55-1.68 and 0.02-0.07, respectively, for these cases (Ansmann et al., 2000; Müller et al., 2003). The mean refractive index derived from the inversion of the smoke data sets was found to be $1.50 \pm 0.07$ (real part) and $0.034 \pm 0.014$ (imaginary part).

The best possibility for a comparison of our inversion results is given for in situ measurements of the particle size distribution and of particle optical properties during Falcon flights (Section 2.2 and Weinzierl et al., 2011). The mean and extreme values
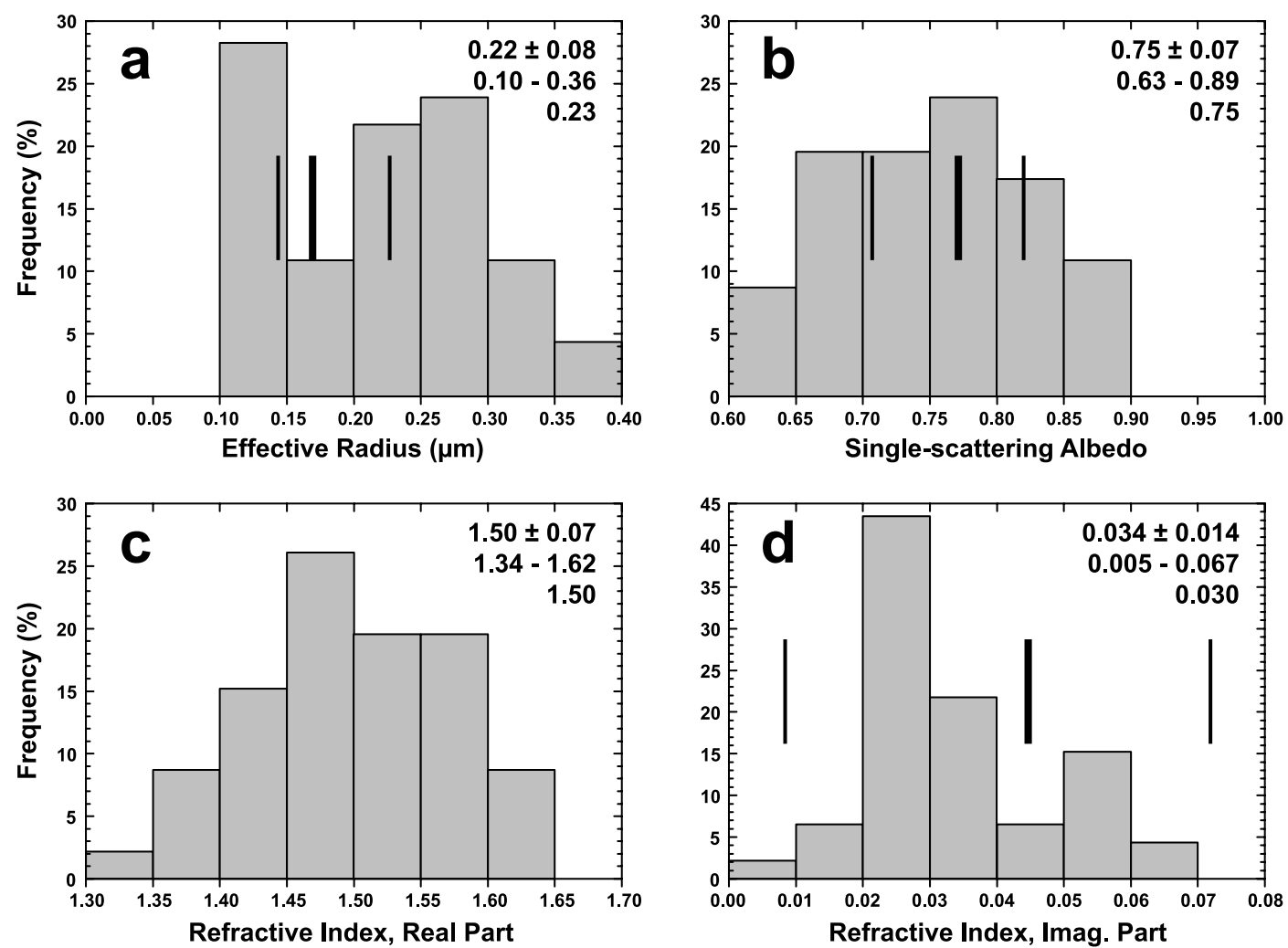

Fig. 10. Frequency distributions of effective radius (a), 532-nm single-scattering albedo (b), and real (c) and imaginary (d) part of the refractive index (at $532 \mathrm{~nm}$ ) for pure biomass-burning smoke derived from inversion of individual measurements at 46 height levels (see Table 1). Numbers in the plots indicate mean, median, standard deviation, and total range of the respective distribution. The bold and thin vertical lines represent the mean and extreme values, respectively, of the fine-mode effective radius, the 530-nm SSA, and the imaginary part of the refractive index (at $530 \mathrm{~nm}$ ) derived from airborne in situ measurements on 22 and 23 January 2008 and 5 and 6 February 2008. 

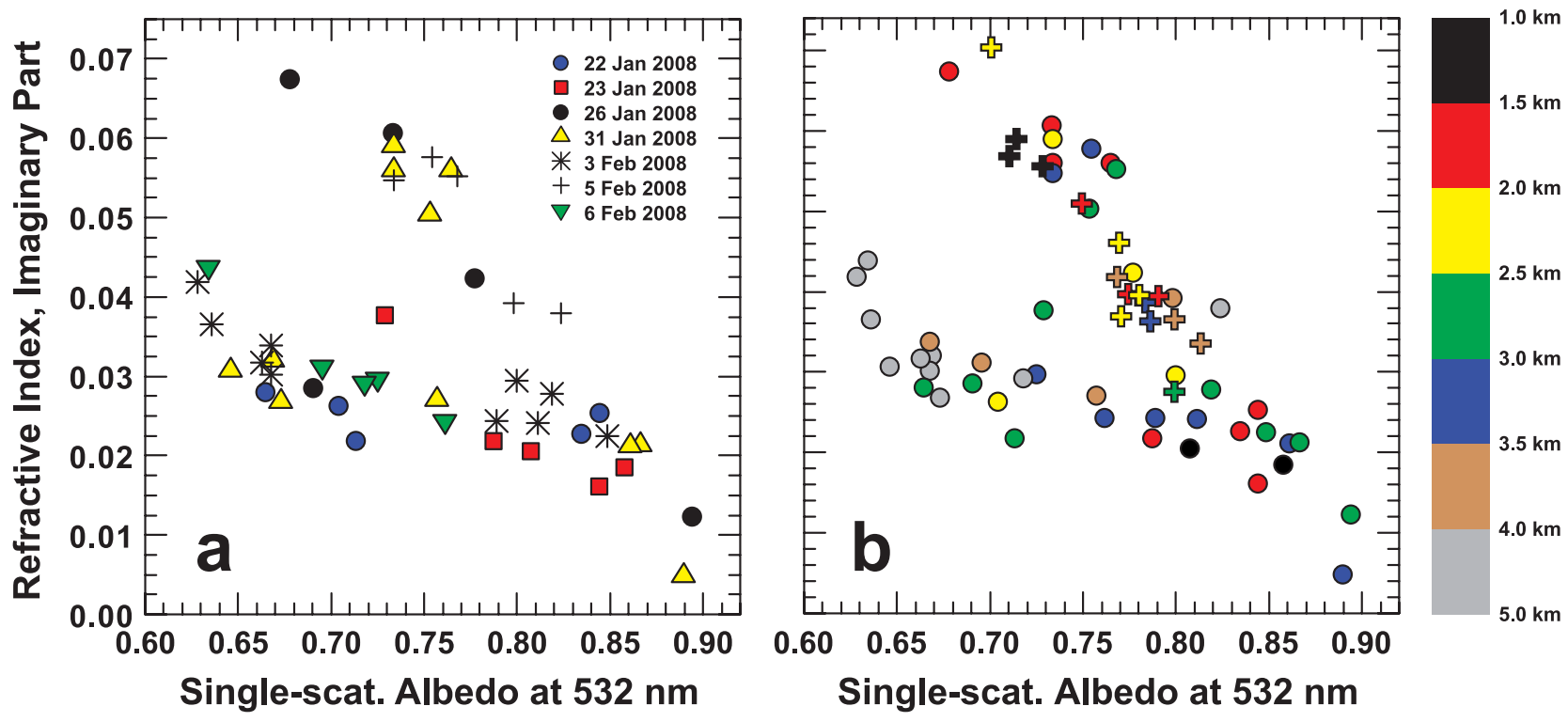

Fig. 11. Correlation plot between the SSA and the imaginary part of the refractive index. Different symbols in (a) denote different measurement days (see Table 1) whereas the colour coding in (b) refers to the height of the measured optical data. The crosses in (b) refer to the Falcon in situ measurements presented in Figs. 41 and 8d, 1, and p.

derived from the in situ observations during the four local flights in the height range of $1-4 \mathrm{~km}$ on 22 and 23 January and 5 and 6 February 2008 (Table 1) are also shown as vertical lines in Fig. 10. The analysis of the Falcon in situ measurements revealed fine-mode effective radii between 0.14 and $0.23 \mu \mathrm{m}$ with a mean value of $0.17 \mu \mathrm{m}$. These values are slightly smaller than the findings of the inversion calculations which suggests that the smoke size distribution exceeds particle radii of $0.5 \mu \mathrm{m}$. In situ observations of the SSA led to values of $0.71-0.82$ at $530 \mathrm{~nm}$ with a mean value of $0.77 \pm 0.03$. Similar values were found from the $3-\lambda$ PSAP inversion at $467 \mathrm{~nm}$ while the mean SSA at $660 \mathrm{~nm}$ was about 0.02 smaller than the value at $530 \mathrm{~nm}$. Note that Johnson et al. (2008a) found values of 0.73-0.93 with a mean value of $0.81 \pm 0.05$ at $550 \mathrm{~nm}$ within biomass-burning smoke layers during DABEX. From the SAMUM-2 aircraft measurements, the imaginary part of the refractive index was found to vary between 0.004 and 0.07 with a mean value of $0.042 \pm$ 0.015 .

Figure 11 shows the correlation of the retrieved values of the SSA and the imaginary part of the refractive index. The symbols and colours refer to (a) the measurement day (see Table 1) and (b) the height interval of the respective input data set. Circles in Fig. $11 \mathrm{~b}$ denote the inversion results while crosses represent the findings of the in situ observations. It is evident that smoke conditions vary from day to day and plume to plume. The bimodal structure of the correlation can be designated to results of different days. 22 January 2008, 23 January 2008, 3 February 2008, and 6 February 2008 show a low slope (i.e. similar imaginary parts for different SSA) while 23 and 26 January 2008 show a high slope (i.e. an increase of the imaginary part with decreasing SSA). The findings of the in situ observations are all located on the branch with the higher slope. Note that the correlation with the lower slope is mostly due to measurements at large heights (grey dots) and may have to do with effects of aging or long-term transport. The results of 31 January 2008 show an indifferent behaviour with values on both branches. Figure $11 \mathrm{~b}$ shows that the stronger increase of the imaginary part with decreasing SSA is found in heights below $2.5 \mathrm{~km}$. The grey dots indicate that generally the SSA seems to be smaller at larger heights. Inversion results for profiles for biomass-burning smoke inferred from the evening measurement of 31 January 2008 are discussed in detail by Tesche et al. (2009b). The findings are compared to observations during AMMA/DABEX, INDOEX, and PRIDE-PRD. The inversion results are in the range of the values published for these campaigns. For example, during AMMA Johnson et al. (2008a) found very low SSA of $0.81 \pm 0.05$ for aged biomass-burning smoke.

However, in situ observations of the SSA (determined from scattering and absorption coefficient measurements, Johnson et al., 2008a; Osborne et al. 2008) do not permit a clear separation of dust and smoke as is possible by means of the polarization lidar technique. As a consequence, in situ measurements of the single-scattering albedo are always influenced by dust particles, which show a very high SSA, even in case of a measured large scattering-related Ångström exponent. This is obviously the main reason for the discrepancy (bias) between lidar-derived and in situ-measured values of the SSA of aerosol layers dominated by biomass-burning smoke. 
A review of the intensive optical properties of biomassburning aerosol as estimated from in situ measurements, forward calculations, and inversion studies is presented by Reid et al. (2005). This paper also gives 'best estimates for median values of smoke optical properties, knowing fully well that each fire has its own character and can deviate significantly from the mean.' The authors present literature values of the SSA (at wavelengths between 450 and $700 \mathrm{~nm}$ ) in the range of $0.60-0.97$ and $0.76-0.93$ for fresh and aged smoke, respectively. The only laboratory study reviewed by Reid et al. (2005) is by Patterson et al. $(1984,1985)$ who report SSA at $550 \mathrm{~nm}$ of $0.74 \pm 0.06$. These values are in the range of our inversion results. Finally, Reid et al. (2005) state that likely values of the single-scattering albedo at $550 \mathrm{~nm}$ are in the range of $0.82-0.92$ with generally higher values for older smoke plumes. The values of the SSA of pure smoke retrieved in our study vary between 0.63 and 0.89 with a mean value of $0.75 \pm 0.07$.

Reid et al. (2005) also point out that for the usual analysis of in situ measurements certain variables need to be varied in a 'reasonable way' to achieve closure of the respective measurement. Mostly, the complex refractive index is the parameter of choice for this variation. After carefully analysing the values used in the literature, Reid et al. (2005) state that by assuming the average size distribution for biomass-burning aerosol the index of refraction appears to be about $1.5 \pm 0.015 \mathrm{i}$. As is shown in Figs. 10c and d, our retrieved mean value of the real part of the refractive index is $1.50 \pm 0.07$. However, we also inferred values as high as 1.62. The retrieved values of the imaginary part of the refractive index show a bimodal distribution with an average of $0.034 \pm 0.014$ that is larger than the value recommended by Reid et al. (2005). Most values are in the range of 0.02-0.04 which leads to a median value of 0.03 which is slightly smaller than the mean value. The range of values spreads between 0.005 and 0.067 .

In another contribution to this Special Issue Heinold et al. (2011) investigate the radiative effects and feedbacks of Saharan dust and biomass-burning smoke by means of modelling studies. They use a smoke SSA of 0.52 at $250-700 \mathrm{~nm}$ which is lower than all field observations of well-aged (or long-range transported) biomass-burning smoke. Future model studies will include our findings of the inversion calculations for a better characterization of the absorptive properties of the biomassburning smoke.

\section{Comparison to further SAMUM-2 in situ observations}

We would like to compare our findings with in situ observations performed in the framework of SAMUM-2. This might be more substantial than the discussion of the literature above, because these measurements were performed at the same time as our lidar observations. An extensive discussion of our findings with respect to previous observations is given in Tesche et al. (2009b) for 31 January 2008 and is also valid for this more general study.

For three local flights in the vicinity of Cape Verde during SAMUM-2 on 25 January 2008, 4 February 2008, and 5 February 2008, Lieke et al. (2011) present height- and sizeresolved observations of particle chemical properties in the vertical column based on aircraft observations. As can be seen in Fig. 6 of Lieke et al. (2011), smoke-dominated layers can easily be identified by the large contribution of soot to the total mass of particles with aerodynamic diameters smaller than $0.5 \mu \mathrm{m} .80-95 \%$ of the particles with $d<0.5 \mu \mathrm{m}$ found at $0.7,2.0$, and $3.3 \mathrm{~km}$ height on 25 January 2008, at 1.3 and $1.8 \mathrm{~km}$ height on 4 February 2008, and at $2.2 \mathrm{~km}$ height on 5 February 2008 were soot particles. No significant contribution of soot to the total aerosol mass for particles larger than a diameter of $0.5 \mu \mathrm{m}$ was found for these layers. This confirms findings of our study: smoke occurs externally mixed with mineral dust in elevated layers and consists of rather small particles (larger particles are mineral dust). The same conclusion was drawn by Eck et al. (2010).

During SAMUM-2 spectrally resolved measurements of the single-scattering albedo and the imaginary part of the refractive index were performed at the surface with a spectral optical absorption photometer (SOAP, Müller et al., 2011). The observations in Fig. 4 of Müller et al. (2011) are grouped to represent different aerosol conditions. Highest SSA of 0.98-0.99 at $550 \mathrm{~nm}$ were measured during a period of pure maritime aerosol at Praia on 9-11 February 2008 (Knippertz et al., 2011; Groß et al. 2011b). The SSA decreased to $0.92-0.95$ during dustdominated days and showed lowest values of $0.84-0.88$ when the authors claim that smoke might have reached down to the surface between 6 and 9 February 2008. Downward mixing as described by Engelmann et al. (2011) may have caused the episodically occurring high smoke concentrations at ground level. The imaginary part of the refractive index at $550 \mathrm{~nm}$ was found to be $0.02-0.03$ during this period. Note that the in situ measurements were performed at $4 \mathrm{~m}$ height above ground level. Even if smoke was mixed down to the surface, it might have only occurred in traces and mixed with dust or local maritime aerosol. This fact might explain the lower values of the SSA and higher values of the imaginary part presented in Fig. 10. As mentioned, from the inversion of the pure smoke data set we inferred a mean smoke SSA of 0.75 and a mean imaginary part of the refractive index of smoke of 0.034. Even though some values were found to be larger than 0.06 , most of the retrieved values of the imaginary part of the refractive index were between 0.02 and 0.03 .

Results of the single-particle analysis of size-resolved aerosol sampling are presented by Kandler et al. (2011). They mostly find real parts of the refractive index of $1.55-1.58$ at $532 \mathrm{~nm}$. Imaginary parts of particles with diameters smaller than $0.5 \mu \mathrm{m}$ were found to be as high as 0.02 while they did not exceed values of 0.009 for larger particles. 


\section{Summary}

We presented optical and microphysical properties of pure smoke aerosol inferred from observations with multiwavelength polarization Raman lidar in the outflow plume of western Africa during SAMUM-2. In this area and during the period of observation in January-February, mineral dust from the Sahara and biomass-burning smoke from southern West Africa are mixed over the burning areas and the Gulf of Guinea before they are transported over the Atlantic ocean to South America in 4-6 km deep layers. To obtain optical properties of the biomass-burning smoke within this complex mixed aerosol plume, the contributions of mineral dust had to be subtracted from the measured total lidar data set by making use of high-quality measurements of the linear particle depolarization ratio. This procedure was applied to seven evening measurements and resulted in 46 individual $3+2$ data sets suitable for inversion calculations to obtain microphysical particle properties.

As theoretically expected, we observed an increase of the lidar ratio and the Angström exponents if the contribution of mineral dust is subtracted from the observations of the aerosol mixture. This corresponds to an increase in particle absorption and a decrease in particle size, respectively. These findings are in agreement with observations during field measurements in similar environment of high loads of combustion aerosol. We found the smoke particles to be rather small and highly absorbing. Retrieved effective radii varied between 0.10 and $0.35 \mu \mathrm{m}$ and showed a mean value of $0.22 \pm 0.08$. Values of the singlescattering albedo ranged from 0.63 to 0.89 with a mean of $0.75 \pm$ 0.07 .

\section{Acknowledgments}

The SAMUM research group is funded by the Deutsche Forschungsgemeinschaft (DFG) under grant FOR 539. We thank the operators of the DREAM model for providing us with vertical profiles of dust concentration during SAMUM-2.

\section{References}

Ångström, A. 1964. The parameters of atmospheric turbidity. Tellus 16, 64-75.

Ansmann, A., Althausen, D., Wandinger, U., Franke, K., Müller, D. and co-authors. 2000. Vertical profiling of the Indian aerosol plume with six-wavelength lidar during INDOEX: A first case study. Geophys. Res. Lett. 27, 963-966.

Ansmann, A., Wagner, F., Müller, D., Althausen, D., Herber, A. and coauthors. 2002. European pollution outbreaks during ACE 2: Optical particle properties inferred from multiwavelength lidar and star-Sun photometry. J. Geophys. Res. 107, doi:10.1029/2001JD001109.

Ansmann, A. and Müller, D. 2005. Lidar and atmospheric aerosol particles. In: LIDAR-Range-Resolved Optical Remote Sensing of the Atmosphere (ed. C. Weitkamp), Springer, New York, 105141.
Ansmann, A., Petzold, A., Kandler, K., Tegen, I., Wendisch, M. and coauthors. 2011. Saharan Mineral Dust Experiments SAMUM-1 and SAMUM-2: What have we learned? Tellus 63B, this issue.

Barbosa, P., Stroppiana, D., Grégoire, J-M. and Cardoso Pereira, J. 1999. An assessment of vegetation fire in Africa (1981-1991): Burned areas, burned biomass, and atmospheric emissions. Global Biogeochem. Cycles 108, doi:10.1029/1999GB900042.

Bauer, S., Bierwirth, E., Wendisch, M., Esselborn, M., Heinold, B. and co-authors. 2011. Airborne spectral radiation measurements to derive single-scattering albedo and solar radiative forcing of Saharan dust mixed with biomass-burning smoke particles. Tellus 63B, this issue.

Bergstorm, R. W., Pilewskie, P., Schmid, B. and Russell, P. B. 2003. Estimates of the spectral aerosol single-scattering albedo and aerosol radiative effects during SAFARI 2000. J. Geophys. Res. 108, doi:10.1029/2002JD002435.

Bohren, C. F. and Huffman, D. R. 1983. Absorption and Scattering of Light by Small Particles. John Wiley, New York, 544 pp.

Campbell, J. R., Welton, E. J., Spinhirne, J. D., Ji, Q., Tsay, S.C. and co-authors. 2003. Micropulse lidar observations of tropospheric aerosols over northeastern South Africa during the ARREX and SAFARI 2000 dry season experiments. J. Geophys. Res. 108, doi:10.1029/2002JD002563.

Capes, G., Johnson, B., McFiggans, G., Williams, P. I., Haywood, J. and Coe, H. 2008. Aging of biomass-burning aerosols over West Africa: Aircraft measurements of chemical composition, microphysical properties, and emission ratios. J. Geophys. Res. 113, doi:10.1029/2008JD009845.

Cooke, W., Koffi, B. and Grégoire, J.-M. 1996. Seasonality of vegetation fires in Africa from remote sensing data and application to a global chemistry model. J. Geophys. Res. 101, 21 051-21 065.

Draxler, R. R. and Rolph, G. D. 2010. HYSPLIT (HYbrid Single-Particle Lagrangian Integrated Trajectory) Model access via NOAA ARL READY Website (http://ready.arl.noaa.gov/HYSPLIT.php). NOAA Air Resources Laboratory, Silver Spring, MD.

Eck, T. F., Holben, B. N., Reid, J. S., Dubovik, O., Smirnov, A. and co-authors. 1999. Wavelength dependence of the optical depth of biomass-burning, urban, and desert dust aerosols. J. Geophys. Res. 104, 31333-31349.

Eck, T. F., Holben, B. N., Ward, D. E., Mukelabai, M. M., Dubovik, O. and co-authors. 2003. Variability of biomass-burning aerosol optical characteristics in southern Africa during the SAFARI 2000 dry season campaign and a comparison of single-scattering albedo estimates from radiometric measurements. J. Geophys. Res. 108, doi:10.1029/2002JD002321.

Eck, T. F., Holben, B. N., Sinyuk, A., Pinker, R. T., Goloub, P. and co-authors. 2010. Climatological aspects of the optical properties of fine/coarse mode aerosol mixtures. J. Geophys. Res. 115, doi:10.1029/2010JD014002.

Engelmann, R., Ansmann, A., Tesche, M., Seifert, P., Althausen, A. and co-authors. 2011. Doppler lidar studies of heat island effects on vertical mixing of aerosols during SAMUM-2. Tellus 63B, this issue.

Franke, K., Ansmann, A., Müller, D., Althausen, D., Wagner, F. and co-authors. 2001. One-year observations of particle lidar ratio over the tropical Indian ocean with Raman lidar. Geophys. Res. Lett. 28, doi:10.1029/2001GL013671. 
Franke, K., Ansmann, A., Müller, D., Althausen, D., Venkataraman, C. and co-authors. 2003. Optical properties of the Indo-Asian haze layer over the tropical Indian ocean. J. Geophys. Res. 108, doi:10.1029/2002JD002473.

Freudenthaler, V., Esselborn, M., Wiegner, M., Heese, B., Tesche, M. and co-authors. 2009. Depolarization-ratio profiling at several wavelengths in pure Saharan dust during SAMUM 2006. Tellus 61B, doi:j.1600-0889.2008.00396.x.

Groß, S., Tesche, M., Freudenthaler, V., Toledano, C., Wiegner, M. and co-authors. 2011a. Characterization of Saharan dust, marine aerosols and a mixture of biomass-burning aerosols and dust by means of multi-wavelength depolarization- and Raman measurements during SAMUM-2. Tellus 63B, this issue.

Groß, S., Freudenthaler, V., Wiegner, M., Greiß, A., Tesche, M. and co-authors. 2011b. Characterization of the planetary boundary layer during SAMUM-2 by means of lidar measurements. Tellus $\mathbf{6 3 B}$, this issue.

Haustein, K., Pérez, C., Baldasano, J. M., Müller, D., Tesche, M. and co-authors. 2009. Regional dust model performance during SAMUM 2006. Geophys. Res. Lett. 36, doi:10.1029/2008GL036463.

Haywood, J. M., Osborne, S. R., Francis, P. N., Keil, A., Formenti, P. and co-authors. 2003. The mean physical and optical properties of regional haze dominated by biomass-burning aerosol measured from the C-130 aircraft during SAFARI 2000. J. Geophys. Res. 108, doi:10.1029/2002JD002226.

Haywood, J. M., Pelon, J., Formenti, P., Bharmal, N., Brooks, M. and co-authors. 2008. Overview of the Dust and Biomass-burning Experiment and African Monsoon Multidisciplinary Analysis Special Observing Period-0. J. Geophys. Res. 113, doi:10.1029/2008JD0 10077.

Heese, B. and Wiegner, M. 2008. Vertical aerosol profiles from Raman polarization lidar observations during the dry season AMMA field campaign. J. Geophys. Res. 113, doi:10.1029/2007JD009487.

Heinold, B., Tegen, I., Bauer, S. and Wendisch, M. 2011. Regional modeling of Saharan dust and biomass-burning Part 1: Model description and evaluation. Tellus 63B, this issue.

Johnson, T. B., Osborne, S. R., Haywood, J. M. and Harrison, M. A. J. 2008a. Aircraft measurements of biomass-burning aerosol over West Africa during DABEX. J. Geophys. Res. 113, doi:10.1029/2007JD009451.

Johnson, T. B., Heese, B., McFarlane, S. A., Chazette, P., Jones, A. and co-authors. 2008b. Vertical distribution and radiative effects of mineral dust and biomass-burning aerosol over West Africa during DABEX. J. Geophys. Res. 113, doi:10.1029/2008JD009848.

Kandler, K., Lieke, K., Benker, N., Küpper, M., Emmel, C. and coauthors. 2011. Electron microscopy of particles collected at Praia, Cape Verde, during the Saharan Mineral dust experiment: Particle chemistry, shape, mixing state and complex refractive index. Tellus 63B, this issue.

Keil, A. and Haywood, J. M. 2003. Solar radiative forcing by biomassburning aerosol particles during SAFARI 2000: A case study based on measured aerosol and cloud properties. J. Geophys. Res. 108, doi:10.1029/2002JD002315.

Knippertz, P., Tesche, M., Heinold, B., Kandler, K., Toledano, C. and co-authors. 2011. Dust mobilization and transport from West Africa to Cape Verde-A meteorological overview of SAMUM-2. Tellus 63B, this issue.
Lieke, K., Kandler, K., Emmel, C., Petzold, A., Weinzierl, B. and coauthors. 2011. Particle chemical properties in the vertical column based on aircraft observations in the vicinity of Cape Verde islands. Tellus 63B, this issue.

Müller, D., Wandinger, U. and Ansmann, A., 1999. Microphysical particle parameters from extinction and backscatter lidar data by inversion with regularization: Theory. Appl. Opt. 38, 2346-2357.

Müller, D., Wagner, F., Wandinger, U., Ansmann, A., Wendisch, M. and co-authors. 2000a. Microphysical particle parameters from extinction and backscatter lidar data by inversion with regularization: Experiment. Appl. Opt. 39, 1879-1890.

Müller, D., Wagner, F., Althausen, D., Wandinger, U. and Ansmann, A. 2000b. Physical properties of the Indian aerosol plume derived from six-wavelength lidar observations on 25 March 1999 of the Indian Ocean Experiment. Geophys. Res. Lett. 27, doi:10.1029/1999GL011217.

Müller, D., Wandinger, U., Althausen, D. and Fiebig, M. 2001. Comprehensive particle characterization from 3-wavelength Raman-lidar observations: Case study. Appl. Opt. 40, 48639-4869.

Müller, D., Franke, K., Ansmann, A., Althausen, D. and Wagner, F. 2003. Indo-Asian pollution during INDOEX: Microphysical particle properties and single-scattering albedo inferred from multiwavelength lidar observations. J. Geophys. Res. 108, doi:10.1029/2003JD003538.

Müller, D., Mattis, I., Wandinger, U., Ansmann, A., Althausen, D. and co-authors. 2005. Raman lidar observations of aged Siberian and Canadian forest fire smoke in the free troposphere over Germany in 2003: Microphysical particle characterization. J. Geophys. Res. 110, doi:10.1029/2004JD005756.

Müller, D., Ansmann, A., Mattis, I., Tesche, M., Wandinger, U. and co-authors. 2007. Aerosol-type-dependent lidar ratios observed with Raman lidar. J. Geophys. Res. 112, doi:10.1029/2006JD008292.

Müller, T., Schladitz, A. and Wiedensohler, A. 2011. Spectral particle absorption coefficients, single-scattering albedos, and imaginary parts of refractive indices from ground based in situ measurements at Cape Verde Island during SAMUM-2. Tellus 63B, this issue.

Myhre, G., Hoyle, C. R., Berglen, T. F., Johnson, B. T. and Haywood, J. M. 2008. Modeling of the solar radiative impact of biomass-burning aerosols during the Dust and Biomass-burning Experiment (DABEX). J. Geophys. Res. 113, doi:10.1029/2008JD009857.

Nickovic, S., Papadopoulos, A., Kakaliagou, O. and Kallos, G. 2001. Model for prediction of desert dust cycle in the atmosphere. J. Geophys. Res. 106, 18113-18129.

Osborne, S. R., Johnson, B. T., Haywood, J. S., Baran, A. J., Harrison, M. A. J. and co-authors. 2008. Physical and optical properties of mineral dust aerosol during the dust and biomass-burning Experiment. J. Geophys. Res. 113, doi:10.1029/2007JD009551.

Patterson, E. M. and McMahon, C. K. 1984. Absorption characteristics of forest fire particulate matter. Atmos. Environ. 18, 25412551.

Patterson, E. M., McMahon, C. K. and Ward, D. E. 1985. Absorption properties and Graphitic carbon emission factors of forest-fire smoke. Geophys. Res. Lett. 13, 129-132.

Pelon, J., Mallet, M., Mariscal, A., Goloub, P., Tanïe, D. and coauthors. 2008. Microlidar observations of biomass-burning aerosol over Djougou (Benin) during African Monsoon Multidisciplinary Analysis Special Observation Period 0: Dust and Biomass-burning Experiment. J. Geophys. Res. 113, doi:10.1029/2008JD009976. 
Pérez, C., Nickovic, S., Baldasano, J. M., Sicard, M., Rocadenbosch, F. and co-authors. 2006a. A long Saharan dust event over the western Mediterranean: Lidar, Sun photometer observations, and regional dust modeling. J. Geophys. Res. 111, doi:10.1029/2005JD006579.

Pérez, C., Nickovic, S., Pejanovic, G., Baldasano, J. M. and Özsoy, E. 2006b. Interactive dust-radiation modeling: A step to improve weather forecasts. J. Geophys. Res. 111, doi:10.1029/2005JD006717.

Petzold, A., Rasp, K., Weinzierl, B., Esselborn, M., Hamburger, T. and co-authors. 2009. Saharan dust absorption and refractive index from aircraft-based observations during SAMUM 2006. Tellus, 61B, doi:10.1111/j.1600-0889.2008.00383.x.

Reid, J. S. and Hobbs, P. V. 1998a. Physical and optical properties of young smoke from individual biomass fires in Brazil. J. Geophys. Res. 103, 32013-32030

Reid, J. S., Hobbs, P. V., Ferek, R. J., Blake, D. R., Martins, J. V. and co-authors. 1998b. Physical, chemical, and optical properties of regional hazes dominated by smoke in Brazil. J. Geophys. Res. 103, 32059-32080.

Reid, J. S., Eck, T. F., Christopher, S. A., Koppmann, R., Dubovik, O. and co-authors. 2005. A review of biomass-burning emissions part III: Intensive optical properties of biomass-burning particles. Atmos. Chem. Phys. 5, doi:10.5194/acp-5-827-2005.

Sassen, K. 2005. Polarization in lidar. In: LIDAR-Range-Resolved Optical Remote Sensing of the Atmosphere, (eds. C. Weitkamp), Springer, New York, 105-141.

Tesche, M., Müller, D., Ansmann, A., Hu, M. and Zhang, Y. 2008. Retrieval of microphysical properties of aerosol particles from onewavelength Raman lidar and multiwavelength Sun photometer observations. Atmos. Environ. 42, 6398-6404.

Tesche, M., Ansmann, A., Müller, D., Althausen, D., Mattis, I. and coauthors. 2009a. Vertical profiling of Saharan dust with Raman lidars and airborne HSRL in southern Morocco during SAMUM. Tellus 61B, doi:j.1600-0889.2008.00390.x.
Tesche, M., Ansmann, A., Müller, D., Althausen, D., Engelmann, R. and co-authors. 2009b. Vertically resolved separation of dust and smoke over Cape Verde by using multiwavelength Raman and polarization lidars during Saharan Mineral Dust Experiment 2008. J. Geophys. Res. 114, doi:10.1029/2009JD011862.

Tesche, M., Groß, S., Ansmann, A., Müller, D., Althausen, D. and coauthors. 2011. Profiling of Saharan dust and biomass-burning smoke with multiwavelength polarization Raman lidar at Cape Verde. Tellus 63B, this issue.

Toledano, C., Wiegner, M., Garhammer, M., Seefeldner, M., Garsteiger, J. and co-authors. 2011. Optical properties of aerosol mixtures derived from sun-sky radiometry during SAMUM-2. Tellus 63B, this issue.

Veselovskii, I., Kolgotin, A., Griaznov, V., Müller, D., Wandinger, U. and co-authors. 2002. Inversion with regularization for the retrieval of tropospheric aerosol parameters from multiwavelength Raman lidar sounding. Appl. Opt. 41, 3685-3699.

Virkkula, A., Ahlquist, N. C., Covert, D. S., Arnott, W. P., Sheridan, P. J. and co-authors. 2005. Modification, calibration, and a field test of an instrument for measuring light absorption by particles. Aero. Sci. Technol. 39, doi:10.1080/027868290901963.

Virkkula, A. 2010. Correction of the calibration of the 3-wavelength Particle Soot Absorption Photometer (3ג PSAP). Aero. Sci. Technol. 44, doi:10.1080/02786826.2010.482110.

Wandinger, U., Müller, D., Böckmann, C., Althausen, D., Matthias, V. and co-authors. 2002. Optical and microphysical characterization of biomass-burning and industrial-pollution aerosols from multiwavelength lidar and aircraft measurements. J. Geophys. Res. 107, doi:10.1029/2000JD000202.

Weinzierl, B., Sauer, D., Esselborn, M., Petzold, A., Veira, A. and co-authors. 2011. Microphysical and optical properties of dust and tropical biomass-burning aerosol layers in the Cape Verde regionAn overview of the airborne in situ and lidar measurements during SAMUM-2. Tellus 63B, this issue. 